\title{
Die Politisierung der Literatur zur Zeit der Weimarer Republik als Problem der literaturgeschichtlichen Darstellung und Wertung
}

\section{Vorbemerkung}

In seinem vorzüglich orientierenden Eingangsreferat hat Timo Felber zwei wichtige Aspekte für eine gesellschaftsbezogene Literaturgeschichtsschreibung benannt: erstens die Relation Text / Kontext oder Werk / Gesellschaft und, damit verschränkt, zweitens die Relation Autonomie / Funktion oder Literaturbezug / Gesellschaftsbezug. Im Folgenden soll an einigen Beispielen aus der Zeit der Weimarer Republik beobachtet werden, wie sich diese Relationen unter dem damals vordringlichen Postulat der Politisierung der Literatur gestalteten und welche Probleme sich daraus für die literaturgeschichtliche Darstellung und Wertung ergeben. Das sei zunächst mit einigen thesenhaft knappen Sätzen umrissen:

(1) Die Politisierung führt in vielen Fällen zu einem Kurzschluss zwischen Text oder Werk und Kontext oder Gesellschaft. Die Autoren greifen aktuelle gesellschaftliche Probleme auf und wollen mit ihren Texten direkt auf den gesellschaftlichen Umgang mit diesen Problemen einwirken. Literatur wird zum Organon der Politik, was erhebliche Folgen für die Themenwahl und die Gestaltung hat.

(2) Dies bedeutet einerseits eine Erleichterung für die literaturgeschichtliche Darstellung, weil der gesellschaftliche Bezug zumeist leicht erkennbar ist, auch wenn es neben den expliziten oft auch noch andere, weniger manifeste Bezüge geben mag, die erst bei genauerer Durchleuchtung sichtbar werden.

(3) Es bedeutet andererseits eine Erschwernis für die Wertung, weil die Politisierung dazu tendiert, den Kunstcharakter und ästhetischen Wert des Werks zugunsten der politischen Funktion zu modifizieren, und weil die Beurteilung des Werks und speziell seiner politischen Züge immer auch durch den Standort des Beurteilenden bedingt sein wird.

(4) Erschwerend kommt hinzu, dass die starke Politisierung der Literatur der Weimarer Republik unter zwei darstellungs- und wertungsrelevanten, aber bis heute sehr unterschiedlich beurteilten Bedingungen stattfand. Die eine ist

Helmuth Kiesel, Heidelberg 
in den permanent krisenhaften und am Ende katastrophalen ökonomischen und sozialen Verhältnissen zu sehen, die andere im Aufkommen zweier revolutionärer und zugleich totalitärer Ideologien, des Bolschewismus/Kommunismus und des Faschismus/Nationalsozialismus, die, wie am Ende dieses Artikels noch weiter ausgeführt wird, bis heute in unterschiedlicher Weise auf literaturgeschichtliche Darstellungen und Wertungen einwirken.

\section{Politisierung als Grundzug der Literatur der Weimarer Republik}

Die starke und programmatische Politisierung der Literatur ${ }^{1}$ begann, genau genommen, nicht erst mit der deutschen Revolution vom Spätherbst und Winter 1918/19, aus der die Republik hervorging, sondern setzte schon in den Jahren um 1910 ein. Einige Daten, die dies anzeigen, sind das Erscheinen von Heinrich Manns Essay Geist und Tat im Jahr 1911; die Gründung der Zeitschrift Die Aktion durch Franz Pfemfert im selben Jahr; die Publikation von Ludwig Rubiners Essay Der Dichter greift in die Politik im folgenden Jahr 1912; die Gründung der Zeitschrift Die Revolution durch Erich Mühsam und andere im Jahr 1913; die Gründung des Ziel-Bundes 1914 und des Ziel-Jahrbuches 1916 durch Kurt Hiller unter dem Motto »Politisierung des Geistes« zwecks »Vergeistigung der Politik«. Ein Text, in dem die Tendenz zur Politisierung der Dichtung auf besonders eindrucksvolle Weise zum Ausdruck kommt, ist Johannes R. Bechers freirhythmisches Gedicht Eingang (so im Gedichtband An Europa, 1916) oder Vorbereitung (so in Menschheitsdämmerung, 1919/20): ein dithyrambisches Bekenntnis zum politischen Avantgardismus der Dichtung, der allerdings weder ein konkretes Ziel noch ein Programm hat, sondern nur in der großsprecherischen Bekundung des Willens zur umstürzlerischen Agitation besteht:

Der Dichter meidet strahlende Akkorde.

Er stößt durch Tuben, peitscht die Trommel schrill.

Er reißt das Volk auf mit gehackten Sätzen. [...]

Menschheit! Freiheit! Liebe!

1 Die folgende Skizze ist eine Zusammenfassung der einschlägigen Kapitel meiner Geschichte der deutschsprachigen Literatur 1918 bis 1933, München 2017, bes. S. 163-203 und S. 840-995. Auf Nachweise für die genannten Titel wird verzichtet, weil sie bekannt und bibliographisch leicht erfassbar sind, ebenso auf die raumfüllende Auflistung von Forschungsliteratur. 


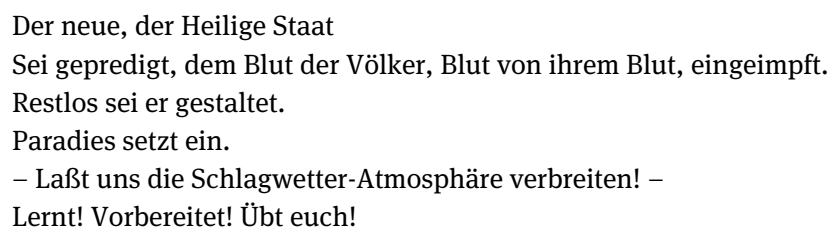

Ausbruch und Verlauf des Ersten Weltkriegs gaben der Tendenz zur Politisierung, die sich in Bechers Gedicht artikuliert, starken Anlass und dauerhafte Motivation. »Der Krieg", so Thomas Anz und Joseph Vogl im Nachwort zu ihrer Anthologie Die Dichter und der Krieg, »bot den Dichtern die Möglichkeit, die ungeliebte Passivität im politischen Geschehen aufzugeben und die Rolle des politisch bedeutsamen Tätigen zu übernehmen «. ${ }^{2}$ Dabei kam es zu einem bemerkenswerten Einstellungswandel, der von der impulsiven und fast vor-politisch zu nennenden patriotischen oder nationalistischen Affirmation des vermeintlichen Verteidigungskrieges zur kritischen Auseinandersetzung mit dem Krieg führte. Diese war vor allem humanitär motiviert, erhielt aber spätestens 1916, als vorübergehend nach diplomatischen Auswegen aus dem festgefahrenen Krieg gesucht wurde, und erst recht 1917, als die russische Februar-Revolution die Zarenherrschaft beendete, eine dezidiert politische Qualität, insofern nun die Möglichkeit eines politischen Systemwandels am Horizont zu erkennen war und das politische Bewusstsein der Autoren schärfte. Das ist nicht nur an der Kriegslyrik gut ablesbar, sondern ebenso gut auch an der Essayistik und an dramatischen und epischen Werken. Alfred Döblin möge als erstes Beispiel dienen, Thomas Mann - später - als ein weiteres:

Mustert man Döblins essayistisches Werk, so stellt man fest, dass es vor 1914 wohl eine beachtliche Anzahl von Artikeln zu künstlerischen und medizinischen Fragen gibt, aber - abgesehen von der 1896 entstandenen und nicht publizierten, zwischen Erzählung und Essay oszillierenden Prosaskizze Modern. Ein Bild aus der Gegenwart - keine politischen Einlassungen. Der erste, dezidiert politische Essay stammt vom Herbst 1914, trägt den Titel Reims und ist eine Apologie der Beschießung der Kathedrale von Reims im September 1914, die damals große Empörung hervorrief. ${ }^{3}$ Danach konzentrierte sich Döblin in der Zeit, die ihm sein ärztlicher Dienst an der Westfront ließ, auf die Arbeit an zwei Romanprojekten (Ölmotor-Projekt und Wallenstein) und äußerte sich politisch erst wieder nach der russischen Februar-Revolution mit dem Essay Es ist

2 Die Dichter und der Krieg: deutsche Lyrik 1914-1918. Hg. von Thomas Anz und Joseph Vogl. Stuttgart 2014, S. 88.

3 In: Alfred Döblin: Schriften zur Politik und Gesellschaft. Hg. von Heinz Graber. Olten 1972, S. $17-25$. 
Zeit!, der im August 1917 in der Neuen Rundschau erschien. ${ }^{4}$ Er verbindet Hoffnung auf Frieden und auf eine große, geistgeleitete Umwälzung mit einem Lob auf die im Krieg angeblich entstandene deutsche »Volksgemeinschaft«, die sich nun auch in der kommenden Zeit der Umwälzung bewähren müsse. Danach kam es erneut zu einer - nur einmal, im Januar 1918, unterbrochenen - Pause, die durch die Revolution beendet wurde. Ab dem Frühjahr 1919 reflektierte Döblin die Gründungskämpfe der Republik mit einer nicht abreißenden Folge von politischen Artikeln, die in verschiedenen Organen erschienen, teilweise unter dem tendenzanzeigenden nom de guerre »Linke Poot «. ${ }^{5}$ Auch in späteren Jahren zeigte sich Döblin in seinen essayistischen Schriften und dichterischen Werken, nicht zuletzt in seinem Roman Berlin Alexanderplatz (1929), als ein politisch und sozial sowohl reflektierter als auch ambitionierter Autor, und dies in so hohem Maße, dass er im Juli 1930 von dem Studenten Gustav René Hocke in einem »offenen «, im Berliner Tage-Buch publizierten Brief gebeten wurde, der jungen Generation »Einsicht« in die Bedingungen und Aufgaben ihrer Existenz zu verschaffen. ${ }^{6}$ Daraus ergab sich eine politischphilosophische Artikelserie, die 1931 unter dem Titel Wissen und Verändern! bei S. Fischer als Buch erschien und noch im selben Jahr fünf Auflagen erreichte.

Begünstigt wurde die an Döblin (und anderen ${ }^{7}$ ) zu beobachtende Politisierung der Literatur durch zwei Umstände. Der eine ist im Wegfall der Zensur zu sehen, die ja durch die Revolution außer Kraft gesetzt und mit dem Artikel 118 der »Weimarer "Verfassung des Deutschen Reichs formell abgeschafft wurde; einzelne staatsanwaltschaftliche Verbote und polizeiliche Beschlagnahmungen oder auch Inhaftierungen änderten daran nichts. ${ }^{8}$ Begünstigend wirkten zum anderen die Gründung von - meist kurzlebigen - Zeitschriften mit politischer Ausrichtung und die Öffnung älterer Zeitschriften für politische Artikel. Für letzteres ist die seit 1905 bestehende Zeitschrift Die Schaubühne ein Beispiel. Sie war zunächst eine reine Theaterzeitschrift, erschien ab September 1914 aber mit einem politischen Leitartikel, erhielt 1917 den Untertitel »Wochenschrift für Politik, Kunst, Wirtschaft« und wurde 1918 bei gleichbleibendem Untertitel in Die Weltbühne umbenannt.

4 Ebd., S. 25-33.

5 Die Artikel finden sich in dem oben genannten Band Schriften zur Politik und Gesellschaft und in Alfred Döblin: Der deutsche Maskenball von Linke Poot. Hg. von Heinz Graber. Olten, Freiburg i.Br. 1972, S. 7-124, einige auch in Alfred Döblin: Kleine Schriften I (1902-1921). Hg. von Anthony W. Riley. Olten, Freiburg i.Br. 1985, S. $233 \mathrm{ff}$.

6 Alfred Döblin: Wissen und Verändern! Hg. von Heinz Graber. Olten, Freiburg i.Br. 1972, S. 129 .

7 Thomas Mann z. B.: siehe dazu unten.

8 Weitere Hinweise in meiner Geschichte der deutschsprachigen Literatur 1918 bis 1933, S. $200 \mathrm{ff}$. 
Die weitere Entwicklung - und das heißt: Verstetigung und Forcierung der postrevolutionären Politisierung der Literatur - wurde durch weitere programmatische Vorgaben und Leistungen namhafter Autoren gefördert:

(1) Der Literaturbegriff wurde politisch akzentuiert, was in der zweiten Hälfte der zwanziger Jahre explizit gemacht wurde, so vor allem durch Friedrich Wolfs Essay Kunst ist Waffe! Eine Feststellung (1927), ${ }^{9}$ durch Alfred Döblins Akademie-Ansprache mit dem Titel Kunst ist nicht frei, sondern wirksam: ars militans (1929), ${ }^{10}$ durch Erwin Piscators Rechenschafts- und Programmschrift Das Politische Theater (1929) und durch Bertolt Brechts Konzept eines neuen Theaters unter dem Motto »Der Schrei nach einem neuen Theater ist der Schrei nach einer neuen Gesellschaftsordnung « (Über eine neue Dramatik, 1928). ${ }^{11}$

(2) Wie die Literatur sollte auch die Literaturkritik »Waffe« sein und parteilich gebraucht werden. Walter Benjamin dekretierte 1928 in seiner Einbahnstraße unter der Überschrift »Die Technik des Kritikers in dreizehn Thesen«:

I. Der Kritiker ist Stratege im Literaturkampf. / II. Wer nicht Partei ergreifen kann, der hat zu schweigen. / [...] V. Immer muß ১Sachlichkeit dem Parteigeist geopfert werden, wenn die Sache es wert ist, um welche der Kampf geht. / [...] XI. Kunstbegeisterung ist dem Kritiker fremd. Das Kunstwerk ist in seiner Hand die blanke Waffe im Kampfe der Geister. ${ }^{12}$

(3) Politisierung der Literatur in diesem Sinne implizierte eine entschiedene Hinwendung zu aktuellen politischen und sozialen Vorgängen und Verhältnissen, die Korrektur oder Beseitigung verlangten, wie beispielsweise die gesetzliche Kriminalisierung und inhumane Verfolgung des Schwangerschaftsabbruchs, die Friedrich Wolf mit seinem aufsehenerregenden und zu Protestaktionen führenden Drama Cyankali ( $§ 218$ ) (1929) angriff. Verbunden mit dieser Aktualisierung war nicht nur das starke Anschwellen der »Zeit«-, »Journalisten«- oder »Gebrauchsliteratur «, ${ }^{13}$ sondern auch deren

9 Friedrich Wolf: Gesammelte Werke. Hg. von Else Wolf, Walther Pollatschek. Band 5: Aufsätze 1919-1944. Berlin, Weimar 1967, S. 76-96.

10 Alfred Döblin: Schriften zu Ästhetik, Poetik und Literatur. Hg. von Erich Kleinschmidt. Olten, Freiburg i.Br. 1989, S. 245-251.

11 Bertolt Brecht: Werke: große kommentierte Berliner und Frankfurter Ausgabe. Hg. von Werner Hecht, Jan Knopf, Werner Mittenzwei, Klaus-Detlef Müller. Band 21: Schriften 1. Berlin, Weimar, Frankfurt a.M. 1992, S. 234-239, Zitat S. 238.

12 Walter Benjamin: Gesammelte Schriften. Unter Mitwirkung von Theodor W. Adorno, Gershom Scholem. Hg. von Rolf Tiedemann, Hermann Schweppenhäuser. Band V/1, hg. von Tilman Rexroth. Frankfurt a.M. 1972, S. 108 f.

13 Ebd., S. $194 \mathrm{ff}$. 
Aufwertung und Anerkennung im literarischen Diskurs. Alfred Kerr schrieb über Peter Martin Lampels Drama Pennäler (1929), das eine Schülerrevolte als Gegenstand hat und Reformen anmahnt: »Es ist kein gutes Stück: doch gut ist, daß man solche Stücke bringt. [...] Kurz: wieder ein Nützlichkeitswerk; sehenswert. « ${ }^{14}$ Brecht notierte noch 1938/39, dass Wolfs Cyankali einen erstaunlichen praktischen Erfolg gehabt habe, und dies nicht trotz, sondern wohl wegen seiner antiquierten aristotelischen Bauart. ${ }^{15}$

(4) Gefördert wurde die Politisierung der Literatur nicht zuletzt auch durch Autorenbündnisse, die sich die politische Ausrichtung oder gar Instrumentalisierung der Dichtung zur Aufgabe machten. ${ }^{16}$ Dies wurde von einigen ephemeren Gruppen der revolutionär gestimmten Anfangsjahre versucht, dann von der Gruppe 1925, einem parteipolitisch gemischten »kameradschaftlichen Zusammenschluß«, der 1925 initiiert wurde, um in aktuellen Fragen die Stimme des »Geistes« zur Geltung zu bringen, aber zu keiner kontinuierlichen Arbeit fand und 1927 aus Mangel an Zusammenhalt und Effizienz wieder einging. Erfolgreicher waren kommunistische Initiativen und vor allem der 1928 gegründete Bund Proletarisch-Revolutionärer Schriftsteller (BPRS), der eine beachtliche programmatische, publizistische und verlegerische Tätigkeit entfaltete und mit seiner Zeitschrift Die Linkskurve und seiner Buchreihe Der Rote 1 Mark Roman der kommunistisch ausgerichteten Literatur Gesicht und Gewicht gab. Ihm wurde Ende 1928 der nationalsozialistische Kampfbund für deutsche Kultur (KfdK) entgegengestellt, der literarisch allerdings nicht im Entferntesten so erfolgreich wie der BPRS war. Daneben gab es eine Vielzahl von kleinen und informellen Gruppen etwa um Bertolt Brecht und Walter Benjamin, um die Brüder Ernst und Friedrich Georg Jünger, um den früheren Revolutionär und Nationalbolschewisten Ernst Niekisch oder um den Volkstum-Herausgeber Wilhelm Stapel. Von früh an waren diese Zusammenschlüsse mit der Tendenz zur Frontbildung verbunden, das heißt: zur schroffen Ausformulierung der eigenen Standpunkte und zur polemischen Wendung gegen andere Positionen. Viele Zeitschriften, Bücher und Artikel führten das Wort »Front« im Titel, und 1929 stellte der Publizist Hermann Ullmann in einem Berlin-Buch fest, Deutschland sei gegenwärtig »voll von Fronten«, an denen unablässig

14 Alfred Kerr: Mit Schleuder und Harfe: Theaterkritiken aus drei Jahrzehnten. Hg. von Hugo Fetting. München 1985, S. 479.

15 Brecht: Werke (s. Anm. 1) Band 21/1: Schriften 2. Berlin, Weimar, Frankfurt a.M. 1993, S. 394 (Unmittelbare Wirkung aristotelischer Dramatik).

16 Weitere Hinweise in meiner Geschichte der deutschsprachigen Literatur 1918 bis 1933, S. $840 \mathrm{ff}$. 
gekämpft werde. ${ }^{17}$ Überall war diese Frontbildung zu spüren, wie Johannes R. Becher 1926 in seinem Bürger- und Weltkriegsroman Levisite zu verstehen gab:

Front gegen Front.

Es riß durch -

Und es riß durch bis in die Sprachverbindung hinab, bis hinab auf die gleiche

Erlebnismöglichkeit.

Front gegen Front heißt: Sprache gegen Sprache, Gefühlsausdruck gegen Gefühlsausdruck, heißt Denkart gegen Denkart, heißt Anschauungsform gegen Anschauungsform, heißt Weltbild gegen Weltbild. ${ }^{18}$

\section{Bilanz 1929 und Ausblick}

Eine Bilanz dieser Entwicklung zog der Schriftsteller Hermann Kesser mit einem Artikel, der im Mai 1929 unter dem Titel Die deutsche Literatur zeigt ihr Gesicht in der Weltbühne erschien. ${ }^{19}$ Als »Resultat des Krieges«, so Kesser einleitend, sei »anzusprechen, daß sich die bewußten und verantwortlichen unter den deutschen Schriftstellern der sozialen und politischen Wirklichkeit bemächtig [t]en, von der das deutsche Schrifttum durch einen Graben getrennt gewesen « sei. ${ }^{20}$ Trotz restaurativer Tendenzen um die Mitte der zwanziger Jahre habe sich diese Linie durchgesetzt und das Gesicht der deutschen Literatur grundlegend verändert. Der letzte Abschnitt von Kessers Artikel lautet:

Heute werden die Forderungen des Expressionismus und der aktivistischen Literatur unter Beweis gestellt. Der Stoff ist klar. Krieg, Revolution, Inflation, Kapitalismus, Sozialismus und Kommunismus, das alles zieht als durchgearbeitete und durchgedachte Materie in das Schrifttum ein, das sich durch sanfte amtliche Anerkennungsgebärden nicht mehr von seinem Weg abbringen läßt. Die man Expressionisten nannte, haben Grundsätze verkündet, Ideen und Richtungslinien wurden festgelegt. Ihre Nachfolger gestalten, was als Bild und Gleichnis, als Feststellungsklage und Urteil zu gestalten ist. Nicht mehr durch explodierende Worte, sondern durch unabweisbare Tatsachen. Ohne Makler und Händler vollzieht sich der Einbruch des Lebens in das Schrifttum. Eine Produktion schlägt durch, schlägt sich durch, fällt auf den Alltag. Erobert sich Lebensrecht auf der

17 Hermann Ullmann: Flucht aus Berlin? Jena 1932, S. 11.

18 Johannes R. Becher: $(\mathrm{CHCl}=\mathrm{CH})_{3}$ As (Levisite) oder Der einzig gerechte Krieg. Berlin, Weimar 1969, S. 297.

19 Hermann Kesser: Die deutsche Literatur zeigt ihr Gesicht. In: Die Weltbühne 25 (1929) I, S. 789-793 (21. Mai 1929).

20 Kesser: Die deutsche Literatur (s. Anm. 19), S. 791. 
Bühne, in der Presse, im Buch. Spannt sich über Betriebsliteratur und Gebrauchsschriftstellerei weg. Geht zur deutlichsten Sprache zurück, macht die lange mißbrauchte Sprache wieder ehrlich, verbessert das kriegsbeschädigte Gefühl für die Echtheit der Worte. Schlägt mit der Brutalität, ohne die es in grundsätzlichen Dingen zuweilen nicht abgeht, die Brücke zwischen dem Schrifttum und der Wirklichkeit und sorgt sich nicht um artistische Gleichgewichte. Leistet die weitere Arbeit, die verrichtet werden muß, damit endgültig deutschen Volksgenossen verdeutlicht wird, daß es eine lebendige Literatur ohne Mitbestimmungsrecht, ohne Mitspracherecht an der Form der Gesellschaft nicht gibt. Wirkt unter Verzicht auf Tiefdenkerei auf Gehirn und Vernunft. Und wird Recht behalten, weil sie den Mut hat, ihr Gesicht zu zeigen. ${ }^{21}$

Was Kesser angeblich beschreibt, eher aber betreibt, ist eine Reduzierung der deutschen Literatur auf die politisch und sozial ausgerichtete, realistische und operative Literatur. Themen wie Liebe, Tod, Natur, Religion und Kunst fehlen. Fragen der poetischen Faktur (»artistische Gleichgewichte«) gelten als bedeutungslos. Eine nicht-alltägliche Intellektualität oder Geistigkeit wird als unnötige »Tiefdenkerei« denunziert. Für Rainer Maria Rilke, Gottfried Benn und Oskar Loerke gab es in Kessers Bild der deutschen Literatur wohl keinen Platz. Die Autoren, die er als wegweisend anführt, heißen Erwin Piscator, Peter Martin Lampel und Ernst Glaeser.

Kessers Befund einer durchgreifenden Politisierung der deutschen Literatur war nicht ganz falsch, aber blind für widerstrebende Tendenzen und Leistungen. Es gab Autoren, die dem Politisierungspostulat ausdrücklich widersprachen oder sich ihm weitgehend entzogen; genannt seien Hermann Graf Keyserling, Rainer

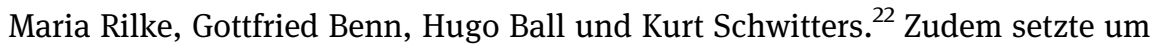
1929 bei jungen Autoren, die in Martin Raschke einen Sprecher und in seiner Zeitschrift Die Kolonne (1929-32) ein Forum fanden, eine Gegenbewegung ein. Der Reduzierung des »modernen Dichtens « auf sozialkritische Reportage und politische Agitation wurde auf dem Titelblatt des ersten Heftes der Kolonne ausdrücklich widersprochen; an Stelle von Politik und Großstadt wurden Natur und ländliches Dasein bevorzugte Themen. Ab 1929 ist - neben dem Weiterbestehen der gesellschaftlich orientierten, aber nicht agitatorischen Literatur, die den Hauptteil der Produktion ausmachte - eine gewisse Polarisierung zu beobachten: Während ein gewisser Teil der Autorenschaft zum Rückzug - man kann auch sagen: zur Befreiung - aus der Politik und engen gesellschaftlichen Bezügen tendierte, steigerten andere Gruppen die Bindung an die extremen, auf einen Umsturz hinarbeitenden politischen Parteien, also die Kommunisten und die Nationalsozialisten, und gingen dazu über, Mobilisierungsliteratur für den handfesten politischen Kampf um

21 Ebd., S. 793.

22 Vgl. dazu meine Geschichte der deutschsprachigen Literatur 1918 bis 1933, S. 176 ff. 
die Vorherrschaft in Betrieben oder Wohnquartieren und für den angestrebten Bürgerkrieg zu produzieren. Vielbeachtete Beispiele sind auf der einen Seite Willi Bredels Romane Maschinenfabrik N. \& K. (1930) und Rosenhofstraße (1931) sowie Walter Schönstedts Roman Kämpfende Jugend (1931), auf der anderen Seite Karl Aloys Schenzingers Roman Hitlerjunge Quex (1932) und Hanns Heinz Ewers' Roman Horst Wessel (1932). ${ }^{23}$

Nach 1933 änderten sich die Bedingungen für die literarische Produktion auf einschneidende und vor allem die Politisierung der Literatur tangierende Weise: In Deutschland und dem Exilland Sowjetunion hatten die Autoren die Wahl zwischen regimekonformer politischer Produktion und politischer Abstinenz, sofern sie nicht zu politischen Bekenntnissen genötigt wurden oder über die Kunst des verdeckten Schreibens verfügten und den Mut dazu aufbrachten. ${ }^{24}$ Autoren, die in einem der freiheitlichen Exilländer Zuflucht fanden, hatten den Vorteil, sich in ihren Schriften politisch mehr oder minder frei äußern zu können oder sich poetisch in politikfernen Seinsbereichen zu bewegen. Letzteres galt freilich als illegitim, insofern »ein Gespräch über Bäume«, wie Brecht in seinem Gedicht An die Nachgeborenen (1939) sagte, in diesen Zeiten »fast ein Verbrechen « war, weil es »ein Schweigen über so viele Untaten« einschloss. Die politisch-kämpferische Ausrichtung des Schreibens wurde nun erst recht zur Pflicht, zu deren Erfüllung Autoren, die ihr nicht nachzukommen schienen, von ihren Kollegen ermahnt wurden; in Hermann Hesses Briefen aus den Jahren nach 1933 spielt die Abwehr des Politisierungspostulats und die Verteidigung der dichterischen Freiheit eine große Rolle. ${ }^{25}$ Verbunden mit diesem nach 1933 erneuerten und verschärften Postulat war im Übrigen ein Wertungssignal, das bis heute nachwirkt. Literatur aus jener Zeit, die sich nicht in erkennbarer oder wenigstens erschließbarer Weise mit deren »Untaten « auseinandersetzt, wird in der Regel nicht mehr wahrgenommen oder muss sich den Vorwurf des Eskapismus gefallen lassen.

23 Weitere Hinweise ebd., S. $911 \mathrm{ff}$. und $959 \mathrm{ff}$.

24 Vgl. hierzu Heidrun Ehrke-Rotermund, Erwin Rotermund: Zwischenreiche und Gegenwelten: Texte und Vorstudien zur >Verdeckten Schreibweise` im `Dritten Reich`. München 1999.

25 Vgl. Hermann Hesse: »In den Niederungen des Aktuellen «: Die Briefe 1933-1939. Hg. von Volker Michels. Berlin 2018, bes. S. 37 ff., 141, 164, 268, 368f., 382, 397 ff., 409f., 419, 450, 453, $514 \mathrm{ff}$. und 633. 


\section{Probleme der Darstellung, Kontextualisierung und Wertung: vier Beispiele}

Im Folgenden seien die Wertungsprobleme, die aus der Politisierung der Literatur resultieren und mir bei der Arbeit an meiner Geschichte der deutschsprachigen Literatur 1918 bis 1933 begegneten, an einer locker aneinandergereihten Folge von Beispielen aufgewiesen und erörtert. Dafür werden zunächst zwei Werke ins Auge gefasst, bei denen man von einer beiläufigen Politisierung sprechen kann (Kurt Tucholskys Schloß Gripsholm (1931) und Thomas Manns Zauberberg (1924)), danach ein Werk der intentionalen Politisierung (Hans Grimms Volk ohne Raum (1926)) und schließlich ein Werk mit möglicherweise starker, aber verdeckter Politikhaltigkeit (René Schickeles Witwe Bosca (1932/ 33)). Deren Erörterung seien drei Beobachtungen vorangestellt:

(1) Die Probleme der Wertung, die mit diesen Texten verbunden sind, sind zugleich auch Beschreibungsprobleme, insofern in die Darstellung gesellschafts- und literaturgeschichtlicher Sachverhalte und in die Beschreibung von Texten, verstanden als inhaltliches Referat und formale Charakterisierung, allein schon durch die Auswahl der berücksichtigten Momente und durch das verwendete Vokabular Wertungen einfließen. Das kann zwar explizit gemacht werden, etwa durch die Benennung des Darstellungsziels und der Auswahlkriterien oder durch die ausdrückliche Reflexion des Vokabulars und die Offenlegung der zugrundeliegenden Forschungsliteratur; aber eine scharfe Trennung von Darstellung und Wertung ist letztlich nicht möglich.

(2) Wertungsprobleme ergeben sich nicht nur aus den in den Texten dargestellten Verhältnissen und Handlungen, die unsere politische oder moralische Reflexion herausfordern, und aus der literarischen Faktur der Texte, die unser ästhetisches Empfinden auf eine überraschende oder verunsichernde Weise ansprechen, sondern auch aus den real- und literaturgeschichtlichen Kontexten, die auf die Wahrnehmung der betrachteten Texte einwirken, so zum Beispiel die durchgängige soziale Not zur Zeit der Weimarer Republik oder der prinzipiell verbrecherische Charakter des NS-Regimes. Von solchen Kontexten ganz abzusehen und ein Werk für sich allein wahrnehmen und gelten lassen zu wollen, ist bei einer literaturgeschichtlich ausgerichteten Betrachtungsweise per definitionem nicht möglich: Literaturgeschichte, und zumal eine gesellschaftsgeschichtlich fundierte, verlangt die Berücksichtigung diachroner Kontexte, die in gedruckten Büchern gegenwärtig sind, und synchroner Kontexte verschiedener Art; sie ist wesentlich »Beziehungssinn«, wie es Uwe Japp 1980 in einem glanzvollen und leider vergessenen 
Buch dargelegt hat. ${ }^{26}$ Die Kontexte, die dafür zu berücksichtigen sind, lagern sich - so ist mit einem von Manfred Engel jüngst beschriebenen und erörterten Modell zu sagen ${ }^{27}$ - gleichsam in »konzentrischen Kreisen « und gestaffelten Zonen der sachlichen und zeitlichen Nähe oder Entfernung um ein Werk. Sie sind aber, wie Engel zu Recht betont, "nicht einfach vorliegende Objekte«, sondern müssen aufgesucht und ausgewählt und als einschlägig erwiesen werden, »entstehen also erst durch komplexe Interpretationsakte «. ${ }^{28}$ Dabeigibtesselbstverständlichreal-und literaturgeschichtliche Umstände, die sich dem Blick allein schon durch das Erscheinungsjahr des betreffenden Werks, dann aber auch durch Sujet, Figuren, Tendenz, Gestaltungsweise oder Stil aufdrängen und bevorzugte Berücksichtigung verlangen; aber immer sind interpretatorisch und wertungsmäßig relevante Entscheidungen nötig, sowohl hinsichtlich der Auswahl der Kontexte als auch hinsichtlich der Nutzung in erhellender, profilierender, limitierender oder eben wertender Absicht. ${ }^{29}$

(3) An allen diesen Beispielen zeigt sich die Bedeutung der NS-Herrschaft und ihrer Verbrechen für die Wertung auch schon der Literatur der Weimarer Republik. Schon die Wahrnehmung eines Textes ändert sich, wenn man sich ins Bewusstsein ruft, dass er im Vorfeld der NS-Diktatur mit ihren schändlichen Vergehen geschrieben wurde. Dabei geht es nicht etwa nur um die Frage und den möglichen Vorwurf der »Wegbereitung «, sondern auch um die Frage der historisch-politischen Sensibilität, also um die Frage, wie viel ein Autor von der unheilvollen Atmosphäre, die ihn umgab, wahrnahm und seinem Werk mitgeben wollte; politische Arglosigkeit spricht gegen literaturhistorische Dignität, bewusste Indolenz erst recht. Besonders heikel werden Darstellung und Wertung bei all den Werken, gegenüber denen der Vorwurf erhoben wurde, sie hätten dem Nationalsozialismus Vorschub geleistet, ein Vorwurf, der beispielsweise auf Erwin Guido Kolbenheyers Paracelsus-Trilogie (1917-26) lastet und durch Kolbenheyers spätere Hinwendung zum Nationalsozialismus legitimiert zu sein scheint. Man liest ein solches Werk von vornherein mit anderen Augen, und sowohl die Darstellung als auch die Wertung wird durch diesen Vorwurf tingiert, selbst dann, wenn man ihn für ungerechtfertigt hielte. Zwar kann man versuchen, eine doppelte Optik walten zu lassen, das heißt, die Werke zu-

26 Vgl. Uwe Japp: Beziehungssinn: ein Konzept der Literaturgeschichte. Frankfurt a.M. 1980.

27 Manfred Engel: Kontext und Kontextrelevanzen in der Literaturwissenschaft. In: KulturPoetik 18 (2018), S. 71-89.

28 Engel: Kontext (s. Anm. 27), S. 74.

29 Eine systematische Darstellung der »Kontextfunktionen« ebd., S. $76 \mathrm{ff}$. 
nächst einmal im Kontext ihrer Entstehungs- und Erscheinungszeit zu sehen und erst in einem zweiten Schritt die weitere geschichtliche Entwicklung und die weitere Positionierung der Autoren zu berücksichtigen; aber natürlich ist es nicht möglich, vom Wissen um das Spätere gänzlich abzusehen. Der Schatten des >Dritten Reichs liegt in unaufhebbarer Weise auf ihnen.

\subsection{Fragwürdige politische Aufladung: Kurt Tucholskys Schloß Gripsholm}

Der Erzählung Schloß Gripsholm ist ein fiktiver kleiner Briefwechsel zwischen Autor und Verleger vorangestellt, in welchem die Entstehung dieser heiteren "Sommergeschichte" (so der Untertitel) auf den Wunsch des Verlegers Ernst Rowohlt zurückgeführt wird, nach einer Reihe umstrittener "politischer Bücher « - man denke an Tucholskys "Bilderbuch « Deutschland, Deutschland über alles (1929), an Arnolt Bronnens O.S. (1929) und an Ernst von Salomons Die Geächteten (1930) - »wieder einmal die sschöne Literatur« zu pflegen«. Mit dem Antwortschreiben willigt der Autor in diesen Wunsch ein. Aber wenn Tucholsky, als er im Spätsommer 1930 den Plan für Schloß Gripsholm fasste, tatsächlich vorgehabt haben sollte, eine reine, politisch so unbeschwerte Sommergeschichte wie Rheinsberg (1912) mit einem idyllischen Handlungsort in Schweden zu schreiben, so hielt er diesen Plan nicht durch: Das Hauptsujet besteht zwar in einer Urlaubsgeschichte in Mariefred am Mälarsee gegenüber Schloss Gripsholm und näherhin in einer »Sommergeschichte« mit Liebesglück zu dreien, nämlich einem Mann und zwei anspruchslos hingabebereiten Frauen; aber dieses Hauptsujet bekommt nach etwa einem Drittel des Gesamttextes ein Nebensujet in der Befreiung eines neunjährigen Mädchens aus einem Kinderheim unter der Leitung einer deutschen, und das heißt selbstverständlich: inhumanen, kinderfeindlichen, kommandier- und strafsüchtigen Erzieherin, einer Mischung aus den militaristischen Typen, die das Deutschland-Buch bevölkern, und den Klein-Despoten, die Tucholsky 1929 in seinem Aufsatz Die Anstalt beschrieb. ${ }^{30}$ Aber gleich, ob dieses zweite Sujet nun von Anfang an geplant war oder während der Arbeit hinzutrat - in jedem Fall wurde Tucholsky von dem Politisierungszwang, der die Zeit der Weimarer Republik beherrschte, erfasst und dazu veranlasst, in die Urlaubsgeschichte, die

30 Kurt Tucholsky: Gesamtausgabe: Texte und Briefe. Hg. von Antje Bonitz, Dirk Grathoff, Michael Hepp, Gerhard Kraiker. Band 11: Texte 1929. Hg. von Ute Maack, Viktor Otto. Reinbek 2005, S. 459-470. 
im Liebesglück zu dreien ihren `Schmelzpunkt ` findet, eine Anstalts-Qualgeschichte einzubauen, die auf den Nationalcharakter der Deutschen ein nicht eben gutes Licht wirft: Immer noch und sogar im Ausland wollen sie an ihrem herrschsüchtigen und sadistischen Wesen die Menschheit genesen lassen. Eine weitere, aber nicht so wichtige historisch-politische Aufladung erfuhr die »Sommergeschichte« durch den Besuch des »alten Kriegskameraden« Karlchen, mit dem Kriegserinnerungen und beiläufig auch Klagen über den versteckt aggressiven Charakter des deutschen »Kleinbürgers « ${ }^{31}$ Einzug in die Erzählung halten.

Wenn man diese Geschichte nicht einfach, wie es meist geschah und geschieht, ${ }^{32}$ als »leckeres Ferien- und Sommerbuch « (Max Herrmann-Neiße) oder dergleichen goutieren will, kommt man für die literaturgeschichtliche Darstellung und Wertung auf Fragen, die nicht leicht zu beantworten sind: Soll man diese Geschichte als »Zwitter« bezeichnen und als »zwiespältig « beschreiben? In welchem Maße profitiert die einfache (um nicht zu sagen: dürftige) Feriengeschichte von der historisch-politischen Aufladung durch den Besuch des Kriegskameraden und die Anstaltsgeschichte? Und in welchem Maße profitiert umgekehrt diese ebenfalls simple und zudem wenig glaubwürdige Anstaltsgeschichte von der Verquickung mit der Ferien- und Liebesgeschichte? Welche sozialpsychologische Repräsentanz kommt der Figur der Anstaltsleiterin zu? Ist in ihr eine Denunziation oder eine Enthüllung des deutschen Nationalcharakters zu sehen? Warum wird nur die Anstaltsleiterin in den Blick gerückt und nicht auch die reiche, in der Schweiz lebende Mutter, die das Mädchen an diesen Schreckensort abgeschoben hat? Welche historische Berechtigung und Notwendigkeit kommt der Anstaltsgeschichte $\mathrm{zu}$ ? Ist sie als faktisch gedeckter und nötiger Hinweis auf notorische Missstände in diesem Bereich zu verstehen? Wie viel verdankt sie möglicherweise der 1928/29 durch Peter Martin Lampels Dramen Revolte im Erziehungshaus und Pennäler ausgelösten und lange anhaltenden Debatte über Heimerziehung und Schulterror? Ist die Kombination von Liebesgeschichte und humanitärer Rettungsgeschichte psychologisch und pragmatisch als geglückt und überzeugend zu bewerten, oder laufen die beiden Stränge etwas gezwungen nebeneinander her und behindern sich wechselseitig, insofern weder das ins Politische hineinragende und damals brisante Thema der deutschen Mentalität noch das damals moralisch herausfordernde Thema der erotischen Libertinage richtig entfaltet wird? Das soll hier gar nicht entschieden werden. Es reicht festzustellen, dass die eigentlich nicht notwen-

31 Tucholsky: Gesamtausgabe (s. Anm. 30) Band 14: Texte 1931. Hg. von Sabina Becker. Reinbek 1998, S. 204.

32 Vgl. Beckers Überblick über die Rezeption: ebd., S. 582f. 
dige, aber zeitgemäße und dem Politisierungszwang gehorchende Aufladung der Feriengeschichte mit Kriegserinnerungen und Deutschtumskritik zu einem Wertungsproblem führt, bei dem historisch-politische und ästhetische Fragen einander durchdringen und schwerlich befriedigend zu lösen sind, weil neben historischem Wissen und ästhetischer Kompetenz zweifellos der historisch-politische Standort und Blick des Wertenden eine Rolle spielt: Wer Tucholskys Deutschlandkritik, wie sie in seinen zahllosen Artikeln entfaltet wurde und in seinem »Bilderbuch « Deutschland, Deutschland über alles prägnanten Ausdruck fand, für zutreffend hält, wird Schloß Gripsholm vermutlich wesentlich anders beurteilen als jemand, der Tucholskys Deutschlandkritik insgesamt für überzogen hält. ${ }^{33}$ Aber wer möchte dies nach all dem, was nach 1933 geschah, sagen? Gibt ihm die Geschichte nicht recht? War Hitlers Herrschaft nicht das Produkt eben der mentalen Dispositionen und politischen Neigungen der Deutschen, die Tucholsky so oft anprangerte? Dem ist schwer zu widersprechen. Man kann nur relativierend hinzufügen, dass - nach dem Urteil von Zeitgenossen und Historikern - die internationalen politischen und ökonomischen Umstände, die problematische Friedensordnung von Versailles und die sozial folgenschwere Weltwirtschaftskrise, für den Aufstieg Hitlers und die Ermöglichung seiner Herrschaft von erheblicher Bedeutung waren. Das führt von Tucholskys Erzählung weg, spielt aber für die Einschätzung ihrer politischen Implikationen eine wichtige, vielleicht sogar entscheidende Rolle.

\subsection{Anachronistische Politisierung in «bösen« Kontexten: Thomas Manns Zauberberg (Naphta)}

Wie an Schloß Gripsholm ist auch an Thomas Manns Roman Der Zauberberg der Zwang zur Politisierung zu beobachten, und hier führt er auf politisch gefährliches und bis heute vermintes Gelände. Bekanntlich begann Mann mit der Arbeit an diesem Werk ${ }^{34}$ im Juli 1913, also in Zeiten jener »machtgeschützten Innerlichkeit«, ${ }^{35}$

33 Vgl. zu diesem Problemkomplex Riccardo Bavaj: Von links gegen Weimar: Linkes antiparlamentarisches Denken in der Weimarer Republik. Bonn 2000, bes. S. 415-438.

34 Für den Zauberberg wird im Folgenden auf den Textband und den Kommentarband der Großen kommentierten Frankfurter Ausgabe verwiesen: Thomas Mann: Große kommentierte Frankfurter Ausgabe: Werke - Briefe - Tagebücher. Hg. von Heinrich Detering u. a. Band 5.1: Der Zauberberg. Hg von Michael Neumann, und Band 5.2.: Kommentar, von Michael Neumann. Frankfurt a.M. 2002. Zur Entstehungsgeschichte Mann: Der Zauberberg (s. Anm. 34), S. 9 ff. 35 Thomas Mann: Essays. Band 4: Achtung, Europa! 1933-1938. Hg. von Hermann Kurzke, Stephan Stachorski. Frankfurt a.M. 1995, S. 65. 
in denen Politik für Thomas Mann kein Thema war. Weder in seinem erzählerischen Werk noch in seiner Essayistik spielt sie eine nennenswerte Rolle. Das änderte sich, wie an Manns Schriften abzulesen ist und wie er selbst 1944 bekannte, »mit dem Kriegsausbruch von 1914«, der ihn »gewaltsam» mit politischen Fragen in Berührung brachte, für die er »vorher gar kein Organ entwickelt hatte ${ }^{36}{ }^{36}$ Der Krieg, den Mann, vom Militärdienst aus Altersgründen verschont, ab dem Herbst 1914 mit einer Reihe mobilisierender Essays begleitete, war der erste Anlass und Gegenstand seiner politischen Essayistik, zu der auch die sukzessive entstandenen und publizierten Teile der Betrachtungen eines Unpolitischen gehören. ${ }^{37}$ Die sich abzeichnende Niederlage führte zu einem vorübergehenden Bruch. Im Spätsommer 1918, als die Betrachtungen im Druck waren, schrieb Mann die Erzählung Herr und Hund, in der es nur wenige und kaum wahrnehmbare Hinweise auf den Krieg gibt, ${ }^{38}$ und danach machte er sich an die kleine Hexameter-»Idylle« Gesang vom Kindchen über die ersten Lebensmonate und die Taufe der im April 1918 geborenen Tochter Elisabeth. Beide sollten sie, wie sich aus Manns Tagebuchaufzeichnungen ersehen lässt, der »Erholung nach den Mühen des Kriegsbuches« dienen. In diesem Zusammenhang tauchte dann auch der Gedanke auf, die im Sommer 1915 mit dem »Hippe«-Kapitel abgebrochene Arbeit an der Sanatoriumsgeschichte wiederaufzunehmen, was im April 1919 auch geschah. Sie als politikferne Tannhäuserund Venusberggeschichte, als welche sie geplant war, fortzuführen, war allerdings nicht möglich. Die heftigen politischen Auseinandersetzungen der gewalterfüllten Gründungsphase der Republik, an denen sich Mann mit Stellungnahmen, Essays und Reden beteiligte, verlangten Berücksichtigung in einem Werk, das ein »Zeitroman« im Sinne auch eines Epochenromans werden sollte. Zwar blieb es bei den unpolitischen Grundfragen des Romans (Was ist die Zeit?; ${ }^{39}$ »Was ist der Mensch «?; $;^{40} »$ Was ist der Körper «?; ${ }^{41}$ »Was war das Leben? «; ${ }^{42}$ Was geschieht nach dem Tode ${ }^{43}$ ), und die Antworten auf sie werden von politikfer-

36 Thomas Mann: Essays. Band 5: Deutschland und die Deutschen 1938-1945. Hg. von Hermann Kurzke, Stephan Stachorski. Frankfurt a.M. 1994, S. 253.

37 Was dieser »Kriegsdienst mit der Feder« für das Schaffen und die Autorschaft Thomas Manns und anderer Autoren jener Zeit (Hauptmann, Hofmannsthal, Rilke, Döblin, Benn, Musil u. a.) bedeutete, zeigt ausführlich Alexander Honold: Einsatz der Dichtung: Literatur im Zeichen des Ersten Weltkriegs. Berlin 2015.

38 Vgl. Honold: Einsatz der Dichtung (s. Anm. 37), S. $383 \mathrm{ff}$.

39 Mann: Der Zauberberg (s. Anm. 34), S. 157 ff.

40 Ebd., S. 245.

41 Ebd., S. 403.

42 Ebd., S. $416 \mathrm{f}$.

43 Ebd., S. 660 f. 
nen Figuren gegeben (Hofrat Doktor Behrens und Mynheer Peeperkorn). ${ }^{44}$ Aber mit dem Humanisten und Republikaner Lodovico Settembrini bekam der Roman einen homo politicus, der zunächst die Gespräche dominieren durfte, dann aber in dem düsteren Leo Naphta einen mindestens ebenbürtigen Kontrahenten erhielt. Spätestens mit dem Auftreten Naphtas (nach der ersten Hälfte des Textes und, entstehungsgeschichtlich gesehen, im Sommer 1922, ${ }^{45}$ als Walther Rathenau ermordet wurde und Thomas Mann vollends zum Republikaner wurde) wird der Zauberberg zu einem aktuellen politischen Roman; denn mit Naphta erscheint eine Figur, die weniger in die Vorkriegszeit passt, in welcher die Romanhandlung spielt, als vielmehr in die frühen zwanziger Jahre, in denen unter dem Eindruck der bolschewistischen Revolution einerseits und der Krisenerscheinungen in der westlichen Welt andererseits chiliastische und totalitäre Ideen um sich griffen. Naphta ist eine ausgesprochen anachronistische Figur, motiviert durch die Absicht, aus dem Vorkriegs- und Sanatoriumsroman, der sich um Grundfragen der menschlichen Existenz gedreht hätte, einen Roman zu machen, der den politischen Problemen und Debatten der Jahre um 1922 gerecht wurde.

In Naphta vereinigen sich vielerlei zunächst disparat wirkende Momente: Seinem jüdischen Vater, einem Schächter, verdankt er neben seinem "geistigen Wühlertum « ${ }^{46}$ die mit Mitleidslosigkeit und Grausamkeit gepaarte »Idee des Heiligen und Geistigen $« .{ }^{47}$ Von der Berührung mit der Sozialdemokratie hat er sein politisches Interesse und seine revolutionäre Neigung, ${ }^{48}$ vom darauf folgenden Anschluss an den Jesuitenorden seine Orientierung an der scholastischen Philosophie und seine Begeisterung für die Idee des Gottesstaats unter päpstlicher Leitung. ${ }^{49}$ Dieser wäre das Gegenteil der aufgeklärten, liberalistischen und kapitalistischen westlichen Gesellschaft: statt desaströser »Massengütererzeugung « Produktion »nach dem Bedürfnis «; ${ }^{50}$ statt Demokratie und humanistischer Bürgerlichkeit, statt Liberalismus und Individualismus, statt Freiheit und Menschenrecht will er »den absoluten Befehl« und »die eiserne

44 Bezeichnenderweise stehen die Gespräche über diese Fragen im Zentrum der großen Untersuchung, die Andreas Kablitz 2017 unter dem Titel Der Zauberberg: die Zergliederung der Welt vorgelegt hat, während die »nicht enden wollenden Diskussionen zwischen Naphta und Settembrini, die einen beträchtlichen Teil des Romans ausfüllen und die zu keinem Ergebnis zu kommen scheinen« (ebd., S. 22) nur im Kapitel über die Juli-Krise (S. 74 ff.) eine größere Rolle.

45 Vgl. Neumann: Kommentar (s. Anm. 34), S. 40 f.

46 Mann: Der Zauberberg (s. Anm. 34), S. 666.

47 Ebd., S. 664.

48 Ebd., S. 666.

49 Ebd., S. 666f. (Jesuiten) und 608f. (Gottesstaat).

50 Ebd., S. 608. 
Bindung « sowie »Disziplin, Opfer, Verleugnung des Ich, Vergewaltigung der Persönlichkeit«, »Gehorsam «, »Askese« und »Terror «. ${ }^{51} \mathrm{Im}$ Kommunismus und in der Diktatur des Proletariats sieht er die Idee des Gottesstaats wirksam, ja bereits den Übergang zum Gottesstaat. ${ }^{52}$ Für Settembrini ist Naphta ein Vertreter der "schwärzesten Reaktion «, ${ }^{53}$ doch nennt der Erzähler ihn zu Recht auch einen »Revolutionär«. ${ }^{54}$ Die Forschung, die die Genese dieser ausgesprochen »synkretistischen Figur « ${ }^{55}$ rekonstruiert hat, ${ }^{56}$ rückt sie in die Nähe jener intellektuell-politischen Strömung, die in eben diesen Jahren in Erscheinung trat und üblicherweise unter dem wohl von Thomas Mann selbst inaugurierten Begriff der »Konservativen Revolution « behandelt wird. ${ }^{57}$ Naphta ist damit auch der Repräsentant einer Strömung oder Haltung, die von nicht wenigen Historikern zu den Wegbereitern der NS-Herrschaft gerechnet wird. Zudem ist er auch ein Vertreter jener Verbindung von religiösen und politischen Vorstellungen, die in den chiliastisch angehauchten Erlösungsideologien des Kommunismus und des Nationalsozialismus zu sehen ist und diesen, wie Eric Voegelin 1938 verdeutlichte, den Charakter von "politischen Religionen « gab. ${ }^{58}$

\subsubsection{Kontextualisierung 1: »jüdischer Bolschewismus»}

Für eine gesellschaftsgeschichtliche Einschätzung der Naphta-Figur gibt es zumindest zwei Aspekte, die eine gewisse Brisanz bekommen, wenn man sie in ihren ideologischen Kontexten sieht:

Der eine Aspekt besteht in der Verbindung von Judentum und politischem Erlösungsstreben, das, indem es auf die Diktatur des Proletariats setzt und die Anwendung blutiger Gewalt geradezu verlangt, ${ }^{59}$ einen kommunistischen oder bolschewistischen Zug erhält und an die russische Revolution denken lässt,

51 Ebd., S. 603 und 607.

52 Ebd., S. 608.

53 Ebd., S. 611.

54 Ebd., S. 669.

55 Hermann Kurzke: Thomas Mann: Epoche - Werk - Wirkung. München 1985, S. 203.

56 Vgl. außer ebd., S. 201 ff., auch Neumann: Kommentar (s. Anm. 33), S. 40 ff. und 268 ff., sowie den Zauberberg-Artikel von Hans Wysling, in: Helmut Koopmann (Hg.): Thomas-MannHandbuch. Frankfurt a.M. 2005, S. 397-422, hierzu S. 399 ff. und $408 \mathrm{ff}$.

57 Vgl. Kurzke: Thomas Mann (s. Anm. 55), S. 203. unter Verweis auch auf die Selbstbezeichnung Naphtas als »Revolutionär der Erhaltung (S. 556).

58 Vgl. Eric Voegelin: Die politischen Religionen. Hg. von Peter J. Opitz. München, Paderborn 2007.

59 Vgl. Mann: Der Zauberberg (s. Anm. 34), S. 609. 
die, romanintern gesehen, freilich noch keine Rolle spielen darf, weil das Geschehen ja 1914 endet. Dieses Arrangement korrespondiert mit der unmittelbar nach der russischen Revolution aufgekommenen und in ganz Europa verbreiteten These vom »jüdischen Bolschewismus«, die auf den überproportional großen Anteil von Juden in der Führung der revolutionären Bewegungen in Russland und anderen von der Revolution erfassten Ländern referiert. ${ }^{60}$ Hitler, mit dem sie regelmäßig in Verbindung gebracht wird, hat sie nicht erfunden; aber er hat sie schon in der frühen Phase seiner propagandistischen Tätigkeit aufgegriffen und allmählich zu einer wichtigen (und lange nachhallenden) $\mathrm{Pa}$ role des Kampfes gegen das Judentum und den Bolschewismus gemacht. In der historisch-politischen Debatte ist die These umstritten und wird oft als »Mär«, »Mythos« oder schlicht »Lüge« bezeichnet. Doch gibt es in der seriösen historischen Literatur auch einige im Kern plausibilisierende Hinweise, so etwa in Ian Kershaws Höllensturz: Europa 1914-1949, wo im Kapitel über den Stalinismus beiläufig erwähnt wird, dass »Juden sich in ganz Europa überproportional vom Sozialismus angezogen fühlten, den sie als Weg zur Befreiung von Diskriminierung und Verfolgung sahen ${ }^{6}{ }^{61}$ oder im vierten Band der von Michael A. Meyer und Michael Brenner im Auftrag des Leo Baeck Instituts herausgegebenen Deutsch-jüdischen Geschichte in der Neuzeit, wo auf die Affinität von jüdischem Messianismus und sozialistischen Revolutionsideen hingewiesen wird, ${ }^{62}$ neuerdings vertieft in Michael Brenners Buch über Juden und Antisemiten in München zwischen 1918 und 1923. ${ }^{63}$

$\mathrm{Zu}$ Recht macht auch Hans Wysling im Thomas-Mann-Handbuch darauf aufmerksam, dass Mann zur Zeit der Münchener Revolution den Typus des jüdischen Revolutionärs - verkörpert nicht nur durch Eugen Leviné (Wysling), ${ }^{64}$ sondern auch durch Kurt Eisner, Gustav Landauer, Ernst Toller und Erich Mühsam - vor Augen hatte und mit einem deutlichen Ressentiment, das im Übrigen auch dem Bolschewismus galt, betrachtete. ${ }^{65}$ Am 2. Mai 1919, als Reichswehrt-

60 Die Literatur dazu ist so umfangreich, dass es weder nötig noch sinnvoll ist, auf den einen oder anderen der einschlägigen Titel zu verweisen. Das Internet bietet unter dem Stichwort »jüdischer Bolschewismus« eine große Fülle von Artikeln mit unabsehbar vielen Hinweisen.

61 Ian Kershaw: Höllensturz: Europa 1914-1949. München 2016, S. 370.

62 Deutsch-jüdische Geschichte in der Neuzeit, Band IV: Aufbruch und Zerstörung 1918-1945. Hg. von Michael A. Meyer unter Mitwirkung von Michael Brenner. München 1997, S. $28 \mathrm{ff}$.

63 Michael Brenner: Der lange Schatten der Revolution: Juden und Antisemiten in Hitlers München 1918-1923. Berlin 2019, bes. S. $21 \mathrm{ff}$.

64 Wysling: Zauberberg (s. Anm. 56), S. 410.

65 Zudem hatte Mann auch den in Berlin agierenden Karl Radek vor Augen, ebenso Rosa Luxemburg: vgl. Thomas Mann: Tagebücher 1918-1921. Hg. von Peter de Mendelssohn. Frankfurt a.M. 1979, S. 124,127. 
ruppen und bayerische Schützenverbände die Räterepublik blutig niederschlugen, schrieb er in sein Tagebuch:

\begin{abstract}
Wir sprachen auch von dem Typus des russischen Juden, des Führers der Weltbewegung, dieser sprengstoffhaften Mischung aus jüdischem Intellektual-Radikalismus und slawischer Christus-Schwärmerei. Eine Welt, die noch Selbsterhaltungsinstinkt besitzt, muß mit aller aufbietbaren Energie und standrechtlichen Kürze gegen diesen Menschenschlag vorgehen. ${ }^{66}$
\end{abstract}

Vor diesem Hintergrund und angesichts der Tatsache, dass die These vom »jüdischen Bolschewismus« in den Jahren, in denen Mann die Naphta-Figur konzipierte und in den Roman einführte, politisch virulent war und antisemitisch ausgespielt wurde, ${ }^{67}$ wirkt Naphtas Zuordnung zum Judentum und die Erklärung seiner Blutrünstigkeit aus dem Schächter-Beruf seines Vaters durchaus problematisch. Man könnte sagen, der Zauberberg sei an der Verbreitung des Klischees vom »jüdischen Bolschewismus« nicht unschuldig. Wäre Naphta eine Figur in einem Roman eines als >völkisch indizierten Autors, beispielsweise in Gustav Frenssens Otto Babendiek (1926), wäre diese Anlass für heftige Kritik. Dass dies im Falle des Zauberbergs anders ist, hat seine guten Gründe; Mann ist eben, anders als Frenssen, später nicht als Antisemit in Erscheinung getreten. ${ }^{68}$ Das stillschweigende Ausblenden des diskreditierenden Kontexts und das ebenfalls stillschweigende Absehen von entsprechender Kritik ist aber symptomatisch und bemerkenswert im Hinblick auf die literaturgeschichtliche Urteilsbildung in diesem Bereich.

\title{
4.2.2 Kontextualisierung 2: Ernst Jüngers Arbeiter
}

Der zweite evaluativ interessante Aspekt besteht in der Ausstrahlung und romaninternen Wertung der Naphta-Figur. Das Kapitel, in welchem Naphta seine

\footnotetext{
66 Mann: Tagebücher (s. Anm. 65), S. 223. Starke Worte, die man leicht an ganz anderer Stelle vermuten könnte!.

67 Vgl. Brenner: Der lange Schatten der Revolution (s. Anm. 67), S. 210 und 328 ff., verzeichnet entsprechende Artikel in den Süddeutschen Monatsheften schon für Dezember 1918. Auch Thomas Mann wird in diesem Zusammenhang erwähnt, und zwar auf eine Weise, die ihn als Vertreter einer "Gegenposition« zum Antisemitismus/Antibolschewismus erscheinen lässt (Brenner: Der lange Schatten [s. Anm. 67], S. 238, 256f.).

68 Für Frenssen sei auf seinen 1940 publizierten Lebensbericht verwiesen, der lange Passagen über die angebliche »jüdische Fremdherrschaft « auf dem Gebiet der Literatur um 1930 enthält: Gustav Frenssen: Lebensbericht. Berlin 1940, S. 242 ff.; vgl. dazu Helmuth Kiesel: Moderne und Antimoderne: Gustav Frenssen im Kontext. In: Heinrich Detering, Kai Sina (Hg.): Kein Nobelpreis für Gustav Frenssen: eine Fallstudie zu Moderne und Antimoderne. Heide 2018, S. 21-42.
} 
politischen Vorstellungen entfalten darf, steht unter der Überschrift »Vom Gottesstaat und von übler Erlösung «, ${ }^{69}$ und am Ende dieses langen enthüllenden Kapitels bekräftigt der Republikaner und Humanist Settembrini dieses Urteil des Textes oder auktorialen Erzählers, indem er gegenüber Hans Castorp und Joachim Ziemßen feststellt, dass das, was Naphta anstrebe und propagiere, nicht »die Erlösung vom [sozialen und kulturellen] Übel« bedeute, sondern »üble Erlösung « sei. ${ }^{70}$ Das explizite romaninterne Urteil über den »wollüstigen« Revolutionsapologeten wirkt also eindeutig, wird aber, wie mir scheint, durch die Darstellung Naphtas konterkariert: Gegenüber dem fadenscheinig gekleideten und ärmlich behausten "Schwätzerchen « Settembrini erscheint Naphta, gut gekleidet und in einem luxuriös ausgestatteten Appartement mit eindrucksvoller sakraler Anmutung wohnend, als ein zwar düsterer, aber faszinierender Herr, den der Erzähler nicht umsonst einmal einen »Aristokrat[en] « ${ }^{71}$ nennt. Sein Porträt ist umfassender und zugleich kompakter als das seines Kontrahenten Settembrini, seine geradezu abenteuerliche, aber wiederum faszinierende jüdisch-sozialrevolutionär-jesuitisch geprägte Sozialisation wird ebenfalls ausführlicher und kompakter dargestellt als Settembrinis Lebensgeschichte, die nur sukzessive und bruchstückhaft vergegenwärtigt wird. Kurz: Wenn es Mann darum ging, zwei um 1922 konkurrierende politische Positionen und Bestrebungen vergleichend vor Augen zu führen, so hat er dem totalitär und terroristisch denkenden »Revolutionär« Naphta entschieden mehr Würde und Ausstrahlungskraft verliehen als dem liberal und humanistisch eingestellten Settembrini. Und wenn dies geschah, um der seinerzeit wachsenden Faszinationskraft sich revolutionär gebender und zugleich totalitär gewillter politischer Bewegungen abbildend Rechnung zu tragen, stellt sich die Frage, ob diese durch eine Figur wie Naphta nicht gesteigert wurde, zumal Settembrinis Zögling Castorp am Ende des Romans und bei Beginn des Kriegs sich ja nicht etwa den pazifistisch und demokratisch eingestellten deutschen Emigranten in Bern oder Zürich zugesellt, sondern dahin eilt, wo ihn Befehl, Bindung, Disziplin, Opfer, Verleugnung des Ichs und Vergewaltigung der Persönlichkeit erwarten. ${ }^{72}$ Und schließlich stellt sich die Frage, wie viel historische Berechtigung oder Notwendigkeit Mann selbst solchen Bewegungen zugestand. Es wäre verkehrt, diese Frage mit Verweisen auf einige antibolschewistische Wendungen in den Tagebüchern der Revolutionszeit, das republikanische Bekenntnis von 1922 und

69 Mann: Der Zauberberg (s. Anm. 34), S. 584.

70 Ebd., S. 621.

71 Ebd., S. 669.

72 Ausführlich dazu Kablitz: Der Zauberberg (s. Anm. 44), S. 74 ff. 
die mehrfach hervorgekehrte Bürgerlichkeit abzuweisen. In den Tagebüchern finden sich auch Eintragungen, in denen Mann sein Verhältnis zum Bolschewismus als »zwiespältig « bezeichnet, ${ }^{73}$ Kapitalismus und Liberalismus für obsolet erklärt ${ }^{74}$ und »etwas Neues in politicis « verlangt, ${ }^{75}$ und im Frühjahr 1932 legte er aus Anlass des Goethe-Jahres in einer Akademie-Rede über das Thema Goethe als Repräsentant des bürgerlichen Zeitalters ein erstaunliches Bekenntnis ab, indem er gegen Ende der Rede sagte:

[...] Im technisch-rationalen Utopismus geht das Bürgerliche in Weltgemeinschaftlichkeit, es geht, wenn man das Wort allgemein genug und undogmatisch verstehen will, ins Kommunistische über. Sie ist nüchtern diese Begeisterung. Aber was heute nottut, ist die große Ernüchterung der Welt, die an verdampften und das Leben hindernden Seelentümern zugrunde geht. [...] Der Bürger ist verloren und geht des Anschlusses an die neu heraufkommende Welt verlustig, wenn er es nicht über sich bringt, sich von den mörderischen Gemütlichkeiten und lebenswidrigen Ideologien zu trennen, die ihn noch beherrschen, und sich tapfer zur Zukunft zu bekennen. Es nützt nichts, die Vernunft zu verhöhnen und einen verstockten Gemüts- und Tiefenkult zu treiben, dessen heutige Gottgeschlagenheit und Lebensverlassenheit sich darin erweist, daß er als eine Art verzweifelter und haßerfüllter Totschlagesentimentalität sich darstellt. Die neue, die soziale Welt, die organisierte Einheits- und Planwelt, in der die Menschheit von untermenschlichen, unnotwendigen, das Ehrgefühl der Vernunft verletzenden Leiden befreit sein wird, diese Welt wird kommen, und sie wird das Werk jener großen Nüchternheit sein, zu der heute schon alle in Betracht kommenden, alle einem verrotteten und kleinbürgerlichdumpfen Seelentum abholden Geister sich bekennen. Sie wird kommen, denn eine äußere und rationale Ordnung, die der erreichten Stufe des Menschengeistes gemäß ist, muß geschaffen sein oder sich schlimmstenfalls durch gewaltsame Umwälzung hergestellt haben, damit das Seelenhafte erst wieder Lebensrecht und ein menschlich gutes Gewissen gewinnen könne. [...] Das Recht auf die Macht ist abhängig von dem historischen Auftrag, als dessen Träger man sich fühlt und fühlen darf. Verleugnet man ihn oder ist man ihm nicht gewachsen, so wird man verschwinden und abtreten, abdanken müssen zugunsten eines Menschentypus, der frei ist von den Voraussetzungen, Bindungen und überständigen Gemütsfesseln, die, wie man zuweilen fürchten muß, das europäische Bürgertum untauglich machen, Staat und Wirtschaft in eine neue Welt hinüberzuführen. Kein Zweifel, der Kredit, den die Geschichte der bürgerlichen Republik heute noch gewährt, dieser nachgerade kurzfristige Kredit, beruht auf dem noch aufrechterhaltenen Glauben, daß die Demokratie was ihre zur Macht drängenden Feinde zu können vorgeben, auch kann, nämlich eben diese Führung ins Neue und Zukünftige zu übernehmen. ${ }^{76}$

73 Mann: Tagebücher 1918-1921 (s. Anm. 65), S. 216 (und 264).

74 Ebd., S. 188, 199, 211.

75 Ebd., S. 166.

76 Thomas Mann: Essays. Band 3: Ein Appell an die Vernunft 1926-1933. Hg von Hermann Kurzke, Stephan Stachorski. Frankfurt a.M. 1994, S. 307-342, hier S. 340 f. 
Der letzte Satz bezeugt, dass Mann an Bürgerlichkeit und Demokratie festhalten wollte. Aber die vorausgehenden Ausführungen sind nahe bei dem, was er seine Naphta-Figur 1924 propagieren ließ und was Ernst Jünger im selben Jahr 1932 mit seinem radikal antibürgerlichen und rücksichtslos technik- und sozialutopischen Mobilisierungsbuch Der Arbeiter herbeireden wollte. Der Weg in eine Welt, so ist dort zu lesen, die mittels technischer Aufrüstung und international geregelter »Erzeugung und Verteilung der Güter « ein menschenwürdiges Leben erlauben werde, führe »über den Arbeitsgang einer Kette von Kriegen und Bürgerkriegen «, ${ }^{77}$ für den ein Kollektiv einordnungs- und aufopferungsbereiter, an Befehl und Gehorsam gewohnter Menschen notwendig sei. ${ }^{78}$ Indem Manns Goethe- und Bürgerlichkeitsrede derartige Vorstellungen als politische Möglichkeit aufruft und ihr zugleich eine gewisse Notwendigkeit zuschreibt, wird der Schluss der Rede ideologie- und literaturgeschichtlich in dreierlei Hinsicht bedeutungsvoll. Erstens gibt er der Naptha-Figur ein neues Gewicht: In ihr offenbarte sich schon 1924 die Faszinationskraft gewaltbereiter Sozial- und Kulturutopien, gegen die auch die bürgerliche Intelligenz nicht ganz gefeit war und die in der Zeit der Weltwirtschaftskrise eine neue Virulenz entfaltete. Zweitens relativiert dieser Redeschluss die oft als exzeptionell eingestufte und kritisierte Antibürgerlichkeit und Inhumanität von Jüngers Arbeiter. Die Verwandlung der bürgerlichen in eine kollektivistische Gesellschaft ist auch für den dezidiert bürgerlich denkenden Thomas Mann eine unabweisbare Forderung der Zeit, die, wenn dies nicht auf demokratischem Weg geschieht, legitimerweise mit revolutionärer Gewalt geschehen wird. Drittens relativiert dieser Redeschluss die negative Bedeutung, die Jüngers Arbeiter für Thomas Mann gehabt haben soll: Immer wieder ist ja zu lesen, dass Jüngers Arbeiter die Vorlage für Figuren und Gedanken der Konservativen Revolution in Thomas Manns Essays und in seinem Doktor Faustus gewesen sei. ${ }^{79}$ Mann hat aber den Arbeiter allenfalls über eine Besprechung in der Neuen Rundschau vom Januar 1933 zur Kenntnis genommen ${ }^{80}$ und

77 Ernst Jünger: Sämtliche Werke. Band 8: Essays II: Der Arbeiter. Stuttgart 1981, S. 83.

78 Jünger: Sämtliche Werke (s. Anm. 77), S. 108 und 154 ff. - Zur weiteren Charakterisierung des Arbeiters und zu seiner Rezeption vgl. meinen Aufsatz: Ernst Jüngers >Arbeiter - Eine Programmschrift der »heroischen Moderne«. In: Jünger-Debatte 2 (2019), S. 123-138.

79 Jürgen Manthey: Ein Don Quichote der Brutalität: Ernst Jüngers `Der Arbeiterく. In: Text + Kritik 105/106: Ernst Jünger. München 1990, sowie Karlheinz Hasselbach: »Das Geheimnis der Identität«. Ernst Jüngers 〉Der Arbeiter` im Licht von Thomas Manns >Doktor Faustus〈. In: Deutsche Vierteljahrsschrift für Literaturwissenschaft und Geistesgeschichte 69 (1995), S. 146-171.

80 Vgl. Lothar Blum: »ein geistiger Wegbereiter und eiskalter Wollüstling der Barbarei«: Thomas Mann über Ernst Jünger - eine Studie zu Manns politisch-literarischer Urteilsbildung. In: Wirkendes Wort 46 (1996), S. 424-445, hier S. 436f. und 444; Helmuth Kiesel: »Wegbereiter 
war, wie die Naphta-Figur und das Ende der Goethe-Rede zeigen, überhaupt nicht auf den Arbeiter angewiesen, um zu entsprechenden Konzepten und Figuren zu kommen. Sie lagen im Rahmen seiner vorausgehenden geschichtlichen Erfahrungen und seiner eigenen politischen Vorstellungsmöglichkeiten womit nicht schon gesagt ist, dass Mann sie präferierte. In späteren Essays mahnte er zwar auch mehrfach eine "soziale Reform « der Demokratie an ${ }^{81}$ und sprach von »sozialen Forderungen der [gegebenen] Weltstunde ${ }^{82}$ die zu einer Überführung des »Demokratische[n] ins Sozialistische« nötigten, ${ }^{83}$ doch hieß sein Ziel nie etwa »Diktatur des Proletariats « oder »Sozialer Autoritarismus«, sondern immer »soziale Demokratie « ${ }^{84}$ oder gelegentlich auch »ökonomische Demokratie ${ }^{85}$

Zusammenfassend ist festzuhalten: Die Politisierung der Literatur oder des literarischen Schaffens durch den Ersten Weltkrieg war nicht rückgängig zu machen. Thomas Manns Rückzug in die Idyllik von Herr und Hund und Kindchen blieb Episode. Der politikferne Vorkriegsroman Der Zauberberg wurde spätestens um 1922 mit der Einführung Napthas zu einem Roman, der neben existentiellen Grundfragen aktuelle und brisante politische Grundfragen thematisierte. Mit Naphta schuf er dafür eine eindrucksvolle Figur, die einige Affinitäten mit prekären Kontexten hat und bei genauer Betrachtung durchaus Anlass für eine politisch-historische Kritik wäre, wie sie in anderen Fällen zweifellos geübt würde. Thomas Mann ist davor durch seine insgesamt demokratische und antifaschistische Einstellung geschützt. Für das Gesamtbild der Literatur der Weimarer Republik und für die Einschätzung anderer Autoren oder Texte wäre es jedoch wichtig, auch diese problematischen Momente des Zauberbergs (und der Goethe-Rede von 1932) stärker zur Kenntnis zu nehmen, als dies bisher der Fall war.

und eiskalter Genüssling des Barbarismus«? Thomas Manns »second hand«-Urteile über Ernst Jünger. In: Jünger-Debatte 4 (2021), S. 97-111.

81 Thomas Mann: Essays. Band 4: Achtung, Europa! 1933-1938. Hg. von Hermann Kurzke, Stephan Stachorski. Frankfurt a.M. 1994, S. 241.

82 Thomas Mann: Essays. Band 5: Deutschland und die Deutschen 1938-1945. Hg. von Hermann Kurzke, Stephan Stachorski. Frankfurt a.M. 1994, S. 14.

83 Ebd., S. 60.

84 Ebd., S. 66, 73, 106 und bes. $233 \mathrm{ff}$.

85 Ebd., S. 274. 


\subsection{Unterschiedliche Wertungen: Hans Grimms Volk ohne Raum}

Ein anderes Problem der literaturgeschichtlichen Wertung soll an Hans Grimms Roman Volk ohne Raum exemplifiziert werden. Es besteht im politisch bedingten Auseinandertreten der zeitgenössischen Urteile über politisch intendierte Werke.

Dem 1926 erschienenen Volk ohne Raum wurde nach 1945 Verantwortung für die nationalsozialistische Raumforderung und Expansionspolitik zugeschrieben. ${ }^{86}$ Diese Verantwortung ist nicht von der Hand zu weisen. Zwar findet sich die Raumforderung schon im ersten Programm der NSDAP vom Februar 1920 und in Hitlers Reden aus den Jahren bis zu seiner Inhaftierung nach dem Putschversuch vom November 1923, ebenso in seinem Buch Mein Kampf von 1925; sie geht also Grimms Roman voraus, doch hat Grimm sie mit dem Titel seines Romans in eine prägnante Formel gefasst und hat ihr mit der Lebensgeschichte seines Helden und mit statistischen Ausführungen eine scheinbare ${ }^{87}$ Plausibilität und zugleich eine starke Melodramatik gegeben. Volk ohne Raum ist ein Buch der Klage: Es zeigt das Leiden deutscher Emigranten in einer feindseligen Welt. Es ist ein Buch des Lobes, das neben der außerordentlichen Tüchtigkeit der Deutschen und der überragenden Qualität deutscher Produkte (bezeugt durch das damals von den Briten als Schutzmarke eingeführte >Made in Germany`) die Aufrichtigkeit und Seelenhaftigkeit der Deutschen rühmt. Es ist ein Buch der Forderung, das für die Deutschen den ihnen gemäßen Raum in der Welt verlangt, ohne jedoch zu sagen, wo er zu finden sei. Es ist ein Buch der Verheißung, das den Führer in eine bessere Zukunft bereits auf dem Weg sieht und viele Leser wohl an den »Trommler« Hitler denken ließ. Und es ist ein Buch der Dichtung als volksbildender Kraft: Deutsche Dichtung wird aufgerufen, um neben der Not die Würde des deutschen Volkes zu verkünden. `Deutscher Stil

86 Vgl. dazu Annette Gümbel: »Volk ohne Raum«: der Schriftsteller Hans Grimm zwischen nationalkonservativem Denken und völkischer Ideologie. Darmstadt, Marburg 2003, sowie Heike Wolter: »Volk ohne Raum«: Lebensraumvorstellungen im geopolitischen, literarischen und politischen Diskurs der Weimarer Republik. Münster, Hamburg, London 2003.

87 Statistisch gesehen war Deutschland sehr viel dichter besiedelt als andere europäische Länder wie zum Beispiel Frankreich (134 gegenüber 72 Einwohnern pro km²), doch lässt sich der Lebensstandard nicht auf die Einwohnerdichte zurückführen; der soziologisch bewanderte Erik Reger, Verfasser der großen Gesellschaftsromane Union der festen Hand (1931) und Das wachsame Hähnchen (1932), bemerkte deswegen in letzterem, die Deutschen seien nicht ein »Volk ohne Raum«, sondern ein »Volk ohne Verstand«: vgl. Erik Reger: Das wachsame Hähnchen. Polemischer Roman. Berlin 1933 [eigentlich 1932, da vordatiert], S. 496 und 517. 
wird vorgeführt, indem vormodernes Vokabular verwendet und an vielen Stellen ein gravitätischer Predigerton angeschlagen wird.

Die Urteile über dieses Buch traten auf eine bemerkenswerte Weise auseinander. Neben zahlreichen rein positiven Besprechungen gab es (zumindest) eine Besprechung, die die politische Tendenz negativ bewertete, die poetische Faktur aber positiv. Sie stammt von Max Herrmann-Neiße, erschien im Oktober 1926 in der Frankfurter Zeitung unter der paradox wirkenden Überschrift Gekonnte Barbarei und beginnt mit dem Satz: „Die umfangreiche Erzählung Volk ohne Raum von Hans Grimm, die sich selbst eine politische nennt, ist formal reif, gekonnt, aber äußerst unangenehm, gefährlich in ihrer tendenziösen Verarbeitung der Geschehnisse. ${ }^{88}$ Das wird weiter ausgeführt: Grimm sei von der »Bauern-« und »Kolonistenauffassung " geprägt, pflege »Rassenüberheblichkeit « und vertrete mit seinem Buch »eine große Gruppe reaktionär verbissener Auslandsdeutscher «. ${ }^{89}$ Dann aber kommt es zu einer Wendung ins Positive, die zunächst den sowohl vom Autor als auch vom Helden verkörperten Charakter würdigt: Der »Vorzug« des Buches bestehe darin,

daß es nicht nur geschrieben, sondern auch erlebt ist; es steht dahinter oder besser davor und haftet mit dem Einsatz der eigenen Tat dafür jener herbe, verbissene, arbeits- und ordnungswütige Schlag deutschen Mittelstandes, dessen Wesenszüge Kargheit, puritanische Selbstherrlichkeit und anspruchsvolle Anspruchslosigkeit sind..$^{90}$

Dem folgt schließlich eine nicht unkritische, aber doch sehr positive Würdigung der literarischen Leistung:

Schreiben, gestalten kann Grimm. Er hat die ursprüngliche Begabung für einen herzhaft schildernden, kernigen, behäbigen Erzählerstil. Einfach, handlich, gediegen baut er seine Welt hin, weniger erfreulich sind die allgemeinen Expektorationen, diese pastorenhaften Apostrophen, weitschweifigen genealogischen und kulturgeschichtlichen Reminiszenzen. [...] Es wäre dringend zu wünschen, daß Dichter freierer, humanerer Gesinnung und weiteren Blicks ebenso kraftvolle Romane schrieben, in denen die Gegenwartsprobleme vom völkerversöhnenden, freiheitlichen, antinationalistischen Standpunkt aus behandelt werden. ${ }^{91}$

Zwei Jahre später, als Volk ohne Raum zum Bestseller geworden war, fühlte sich Kurt Tucholsky zum Einschreiten veranlasst und wandte sich mit einem

88 Max Herrmann-Neiße: Gekonnte Barbarei [zuerst am 31. Oktober 1926 in der Frankfurter Zeitung]. In: Max Herrmann-Neiße: Gesammelte Werke / Die neue Entscheidung: Aufsätze und Kritiken. Hg. von Klaus Völker. Frankfurt a.M. 1988, S. 669-671, Zitat S. 669.

89 Ebd., S. 670.

90 Ebd., S. 670 f.

91 Ebd., S. 671. 
gewichtigen Artikel, der Anfang September 1928 unter dem Titel Grimms Märchen in der Weltbühne erschien, gegen die Kolonialideologie, die er hinter Volk ohne Raum wie hinter Grimms früheren Erzählungen sah. Volk ohne Raum wird nur kurz behandelt, aber gänzlich verworfen, und zwar nicht nur in politischer, sondern auch in literarischer Hinsicht: Es ist für Tucholsky ein »mäßiger Roman« von »dilettantischer Innigkeit«, »protestantischer Provinziallyrik « ${ }^{92}$ und miserablem Stil. Die Sätze, die ihm gewidmet sind, seien zitiert:

Zunächst ist merkwürdig, zu sehn, wie schlecht diese Teutschen schreiben. Ich will gar nicht von dem wahrhaft Morgensternschen Satz reden: »Der Vogel, der im Volksmunde Pfefferfresser und in Wirklichkeit nach seinem Rufe tok, tok, tok Tokan heißt« - dieses sin Wirklichkeit hätte der alte Mauthner erleben sollen. Es sind auch nicht jene Schachtelsätze, die man nur mit allen zehn Fingern lesen kann, auf jeweils einen Nebensatz einen Finger haltend, um den Faden nicht zu verlieren; nicht allein solche Flüchtigkeiten wie: "aber die Begegnungen sind nicht fertig«, was besagen will, daß der Autor sie noch nicht alle aufgezählt hat; [...]. Nein, das allein ist es nicht. Es ist jener seltsame und ekle Stil, den man etwa mit `Grammatik in Latschen ‘ umschreiben könnte, ein Stil, der den Leser gewissermaßen in die Seiten pufft: du weißt schon, wie ichs meine, ich brauche mich nicht so exakt auszudrücken. Traulich duftet es nach süßem Tabak; wann sich Papa zum letzten Mal die Füße gewaschen hat, steht noch sehr dahin, die Frauen haben viel Gemüt und wenig Bidet, und im Garten blühen Himbeeren, Kirschbäume und die deutsche Seele. So ein Stil ist das. ${ }^{93}$

Zwei Fragen stellen sich. Zunächst: Wie ist die Diskrepanz zwischen diesen beiden Urteilen über Grimms Stil zu erklären? Sollte sie nur auf unterschiedliche stilistische Vorlieben und Sensibilitäten zurückzuführen sein, oder erlaubte die politische Ablehnung bei Tucholsky anders als bei Herrmann-Neiße von vornherein keine positive Wahrnehmung und Würdigung des Stils von Volk ohne Raum? Anzunehmen ist Letzteres. Tucholsky nahm sich diesen Roman vor, als er eine für Tucholsky unliebsame Breitenwirkung entfaltete, und fühlte sich sogleich an »Stil und Poesie« von »Pastor Frenssen « erinnert, ${ }^{94}$ einen Hauptvertreter der konservativen oder >völkischen` Dichtung. Kurz: Tucholsky war vermutlich, obwohl er Grimm als einen »im tiefsten Kern anständige[n]«, »saubere[n], aufrechte[n] Mann « einschätzte, ${ }^{95}$ aus Abneigung sowohl gegen die Kolonialschwärmerei als auch gegen den »teutschen« Stil des Konservativismus weder willens noch ästhetisch tolerant genug, um den Stil von Volk ohne Raum

92 Kurt Tucholsky: Grimms Märchen [zuerst am 4. September 1928 in der Weltbühne]. In: Gesamtausgabe (s. Anm. 30), Band 10: Texte 1928. Hg. von Ute Maack. Reinbek 2001, S. 358-368, Zitat S. 358.

93 Ebd., S. 360.

94 Ebd., S. 358.

95 Ebd., S. 358 und 360. 
als respektable literarische Ausdrucksweise gelten $\mathrm{zu}$ lassen, geschweige denn als Leistung anzuerkennen, wie dies bei Herrmann-Neiße der Fall war. Die politische Ausrichtung präformierte das ästhetische Urteil.

Die zweite Frage ist, wie man als Verfasser einer literaturgeschichtlichen Abhandlung mit der Diskrepanz zwischen den Urteilen Herrmann-Neißes und Tucholskys umgeht. Man wird sie beide referieren und versuchen, die Unterschiedlichkeit zu verstehen und zu erklären. Man wird aber auch das Gefühl haben, dass der Leser der Abhandlung ein eigenes Urteil erwartet. Hierfür kann man auf die eigene Leseerfahrung zurückgreifen. Sie spricht in diesem und meinem Fall für Herrmann-Neiße. Wer Volk ohne Raum als geschichtlich interessierter Leser in die Hand nimmt und es nicht mit dem >Vorurteil liest, dass es sich nur um ein national(sozial)istisches Machwerk handeln könne, dem kann es passieren, dass er in diese manchmal etwas umständlich geschriebene, aber doch auch lebendig wirkende, abwechslungsreiche und bewegende Geschichte hineingezogen wird und die stilistischen Schnitzer, die Tucholsky ihr ankreidet, übersieht. Wenn er dann, durch Tucholsky aufmerksam und misstrauisch gemacht, den Text ein zweites Mal unter stilistischen Gesichtspunkten mustert, wird er noch anderes entdecken, was man, wenn man will, monieren kann. Aber machen vereinzelte Ungeschicklichkeiten Volk ohne Raum zu einem stilistisch insgesamt stümperhaften Roman? Und rechtfertigt, was Tucholsky an Beispielen und Argumenten anführt, seine mit primitiven sozialen und zudem misogynen Anspielungen arbeitende Verächtlichmachung von Grimms Stil? Ich glaube nicht. Dennoch kann man Tucholskys Urteil nicht übergehen oder einfach als verfehlt und belanglos abtun. Es muss aus zwei Gründen Erwähnung finden: zum einen, weil es so gut wie das Urteil von Herrmann-Neiße vor Augen führt, wie Zeitgenossen auf Grimms Erzählweise reagieren konnten, und zum andern, weil es als Urteil eines Schriftstellers und Kritikers von Rang und Ausstrahlung auf die Wahrnehmung von Volk ohne Raum dauerhaft einwirkte, nach 1945 mit zunehmender Kraft. Die Beurteilung eines Werks wie Volk ohne Raum kann im Rahmen einer Literaturgeschichte also nur in der kritisch reflektierten Zusammenführung, aber nicht Harmonisierung von zeitgenössischen Wertungen und eigenen Leseerfahrungen bestehen.

\subsection{Folgen verborgener Politik: René Schickeles Die Witwe Bosca}

An diesem letzten Beispiel soll beobachtet werden, was mit Werken geschah und geschieht, die sich den Politisierungserwartungen entzogen oder diesen wenigstens nicht sichtbar entsprachen. Das ist der Fall bei René Schickeles Roman Die Witwe Bosca von 1933. 
René Schickele, der den badischen Nationalsozialisten wegen seiner pazifistischen, liberalen und frankophilen Einstellung - er war gebürtiger Elsässer und hatte eine französische Mutter - ein Dorn im Auge war, übersiedelte im Herbst 1932, als die Angriffe auf ihn zunahmen, von Badenweiler nach Sanarysur-Mer. Dort schrieb er im Frühjahr 1933 den Roman Die Witwe Bosca. Worum es Schickele mit diesem Werk zu tun war, ist aus dem Tagebuch, das er in diesen Monaten führte, ${ }^{96}$ und aus einigen Briefen, aber auch aus einigen diskreten Hinweisen im Roman selbst zu ersehen: Er wollte (1.) den Weggang von Deutschland verschmerzen. Er wollte sich (2.) seine neue Heimat im Küstenstreifen und Bergland zwischen Sanary und Fréjus erschreiben. Und er wollte (3.) eine Gesellschaft zeigen, die, noch unter den moralischen Folgen des vergangenen Kriegs leidend, bereits wieder Vorkehrungen für einen nächsten Krieg traf und auf eine Katastrophe zusteuerte. Bald nach Erscheinen des Romans (im Dezember 1933 bei S. Fischer in Berlin) schrieb Schickele am 17. Februar 1934 an Harry Graf Kessler:

Mit der Witwe Bosca hoffte ich mehr zu tun, als nur ein sablenkendes` Buch zu schreiben. Die todestrunkene Bosheit und Rachsucht einer götzendienerischen, entgotteten Zeit in einer auf der Straße aufgelesenen Gestalt darzustellen - darauf kam es mir an. Ausdrücklich wollte ich jede aktuelle Beziehung vermeiden und das Übel an der Wurzel zeigen. Denn für das, was heute geschieht, bildet die Politik nur den Vorwand - bestenfalls liefert sie das die innerste Triebfeder auslösende Ereignis. Ich sehe in allem die Katastrophe des Menschen, der sein Gewissen verlor. Er hat die alten metaphysischen Bindungen abgelegt, ohne neue zu finden, und rast wie ein zur Unzeit befreiter Sklave. ${ }^{97}$

Der Inhalt des Romans muss hier nicht ausführlich wiedergegeben werden. Folgendes dürfte reichen: Jene Juliette Bosca hat ihren Mann im Ersten Weltkrieg verloren und sich danach in Ranas (Anagramm aus Sanary) niedergelassen. Dort zeigt sie sich auch noch lange Jahre nach dem Krieg - die Handlung ist über Altersangaben auf das Jahr 1932 zu datieren - als unentwegt trauernde Witwe, schwarz gekleidet und verschleiert, mit weiß gepudertem Gesicht, aus dem die rot geschminkten Lippen und zwei ebenfalls rot bemalte Wangen hervorleuchten. Ihre vermeintliche Trauer ist aber nichts anderes als die Camouflage einer durch den Krieg aus der Bahn geworfenen Frau oder femme fatale, deren Sexualgier und Herrschsucht mehrere Personen zum Opfer fallen, bevor sie von einem neuen Gatten nach einem heftigen Streit, bei dem sie nach dem Revolver greift, in Notwehr erwürgt wird. Erzählt wird dies mit einem ungewöhnlichen »Brio« und in einem »epischen Strom» (so Thomas Mann $1939 \mathrm{im}$

96 René Schickele: Die blauen Hefte. Edition und Kommentar. Hg. von Annemarie Post-Martens. Frankfurt a.M., Basel 2002.

97 René Schickele: Werke in drei Bänden. Hg. von Hermann Kesten. Band 3: Dramen [...] Briefe. Köln 1959, S. 1192. 
Vorwort der französischen Ausgabe ${ }^{98}$ ), der »aus lauter Strudeln und Wirbeln besteht « und mit einer Vielzahl von disparaten und teilweise auch bizarren Motiven, grotesken Zuspitzungen und burlesken Episoden aufwartet, ebenso mit ausführlichen Landschaftsschilderungen. Mehrfach werden beiläufig Geschwader von »Bombenflugzeugen« und Marinemanöver mit schwerem Geschützdonner erwähnt, und gegen Ende bemerkt ein hellsichtiger Arzt einmal: »Wir trinken unsern Tee auf einem Pulverfaß. « ${ }^{99}$

Den zeitgenössischen Experten blieb der zeitanalytische Gehalt des Romans, den Schickele in seinem Brief an den Grafen Kessler als hauptsächlichen, wenn auch nur untergründigen Sinn des Werks nannte und der die politische Großwetterlage umfasst, verborgen. Oskar Loerke, der Lektor des Verlags S. Fischer, der den Roman im Herbst 1933 vorgelegt bekam, schrieb damals an Schickele, er sehe nicht, warum man sich jetzt mit solchen »Kuriositäten « befassen solle. Offensichtlich sah er sich durch nichts in dem Roman veranlasst, ihn als Pathographie der Zeit zu verstehen und einzelne Episoden - wie etwa das okkasionelle Zusammentreten der Bevölkerung des Hafenstädtchens, in dem die Handlung spielt, zu einer lockeren Zivilgesellschaft - als Gegenentwurf zur nationalsozialistisch organisierten >Volksgemeinschaft $<$ zu sehen. Der Rezensent der repräsentativen Zeitschrift Die Literatur, der Literaturkritiker und Essayist Werner Schickert, rühmte den Roman »als bedeutendes, ins Zeitlose gesteigertes Kunstwerk«, das aber, weil durch und durch französisch empfunden, den Deutschen in diesem "Schicksalsaugenblick« nichts sagen könne. Diese beiden Reaktionen sind hochgradig symptomatisch und zeigen, dass sich das Interesse von Büchermachern und Vermittlern, wie auch an vielen anderen Fällen zu beobachten ist, in den Jahren um 1933 auf die gesellschaftliche und näherhin politische Funktion von Literatur konzentrierte. Unter diesen Umständen wurde die intentionale Vermeidung der direkten politischen Rede, zu der sich Schickele in seinem Schreiben an den Grafen Kessler ausdrücklich bekannte, für Die Witwe Bosca zum Rezeptionshindernis. Das Werk wurde nicht empfohlen, sondern als verfehlt und belanglos abgetan. Sofern es überhaupt ins Bewusstsein eines breiteren Publikums gelangte, verschwand es bald wieder daraus und geriet in Vergessenheit. Daran änderten auch einige Neuausgaben in der Nachkriegszeit und der Abdruck in der Werkausgabe von 1959 nichts. Man kann nicht sagen, dass Die Witwe Bosca ein Publikumserfolg geworden oder die Aufmerksamkeit der Literaturwissenschaft auf sich gezogen

98 Thomas Mann: Zur französischen Ausgabe von René Schickeles `Witwe Boscar. In: Thomas Mann: Werke: das essayistische Werk. Hg. von Hans Bürgin. Band 2: Schriften und Reden zur Literatur, Kunst und Philosophie. Frankfurt a.M. 1968, S. 322-326.

99 René Schickele: Die Witwe Bosca. Hamburg 1951, S. 255. 
hätte. Es gab keine Rezeption, die fortzusetzen und zu erweitern gewesen wäre; es gab, von Thomas Manns Vorwort zur französischen Ausgabe abgesehen, keine Empfehlungen oder andere Rezeptionsdokumente, die den Roman für die Literaturwissenschaft und Literaturgeschichtsschreibung allgemein interessant und als Reflexion der >Wende` von 1933 wichtig gemacht hätten.

Immerhin gab es zwei - allerdings sehr ungleiche - Rettungsversuche: einen Artikel von Peter Härtling, der Die Witwe Bosca am 6. März 1980 in der Frankfurter Allgemeinen Zeitung im Rahmen der Serie Romane von gestern - heute gelesen rühmend besprach und dabei auch auf die zeitanalytischen Absichten Schickeles hinwies, ohne sie indessen im Roman zu verifizieren, ${ }^{100}$ und die 2002 publizierte Dissertation von Annemarie Post-Martens unter dem Titel PAN-Logismus: René Schickeles Poetik im Jahr der »Wende«1933. Die These dieser bemerkenswerten Untersuchung, die durch die literaturtheoretischen Vorstellungen von Gilles Deleuze und Félix Guattari inspiriert ist, lautet, kurz gesagt, dass es sich bei dem Roman Die Witwe Bosca um ein Werk völlig neuer »Mach-Art« handelt, »die sich für Schickele aus der Zeit selber ergab « ${ }^{101}$ und eine »Poetik [...] für ein»Jahrhundert der Angst $\iota$ und Orientierungslosigkeit zur Einübung in Strategien der Panikbewältigung « darstellt: ${ }^{102}$ Es handelt sich um eine Art von »Rhizom«, »das quasi wie ein Hypertext funktioniert« und deswegen auch eine neue »Lesart« verlangt, nämlich nicht "gradlinig von vorn nach hinten« zu lesen ist, sondern in einem schleifenförmigen Vor- und Rückwärts-Gehen, zudem wie eine »Partitur«, was wohl heißen soll: auf mehreren Ebenen gleichzeitig. ${ }^{103}$ Dafür werden, obwohl Schickele sich am Ende seiner Ursprungsnotiz vom 27. März 1933 eine Vermeidung von Allegorik und Symbolik auferlegte, alle Möglichkeiten der Texterweiterung oder Textüberhöhung genutzt, indem nun eben doch alles, was in Frage kommt, allegorisch oder symbolisch verstanden und gedeutet wird: Namen, Gesten, Orte und Geschehnisse. So wird im Namen »Bosca « ${ }^{104}$ auch der französische Schimpfname für die Deutschen, »Boche«, gesehen, zugleich aber auch das Wort »bosquet«, das

100 Peter Härtling: Ein böses, ungestümes Lied. In: Romane von gestern - heute gelesen. Band 2: 1918-1933. Hg. von Marcel Reich-Ranicki. Frankfurt a.M. 1989, S. 366-372. - Härtling zitiert den oben angeführten Brief Schickeles an den Grafen Kessler, fährt dann aber fort: »Wer von solchen Bezügen, Verstrickungen nicht weiß, liest den Roman anders: Er bleibt auf seine Zeit konzentriert, auf die der Juliettte Bosca und ihres Liebhabers Burguburu « (S. 369). Mit »Zeit« ist aber die Liebes-, Verführungs- und Eifersuchtshandlung gemeint, die dann rekapituliert wird.

101 Vgl. Annemarie Post-Martens: PAN-Logismus: René Schickeles Poetik im Jahr der »Wende» 1933. Frankfurt a.M., Basel 2002, S. 14.

102 Ebd., S. 13.

103 Ebd., S. 9 ff., $69 \mathrm{ff}$. und $198 \mathrm{ff}$.

104 Vgl. ebd., S. $120 \mathrm{ff}$. 
»Wäldchen« oder speziell »Lustwäldchen« bedeutet und mithin als Verweis auf den »verwunschenen Wald « ${ }^{105} \mathrm{zu}$ deuten ist, in dem sich Glück und Unglück der Tochter der Witwe Bosca und ihres Jugendfreundes vollenden sollten. Die Witwe Bosca, die nicht umsonst durch die Farbentrias Schwarz-WeißRot gekennzeichnet ist, steht also für Deutschland, und der »bosquet« (der im Roman allerdings nie mit diesem französischen Wort benannt wird) erweist sich am Ende als ein >Boche`-Wald, der für »das Nazi-Deutschland « steht. ${ }^{106}$ Kurz: Die Kluft zwischen privatem Geschehen und politischen Verhältnissen um 1932/33, zwischen provencalischem Alltag und nationalsozialistischen Bestrebungen scheint überbrückbar zu sein; der Roman lädt den Leser - so eine weitere These dazu ein, diese Entdeckungs- und Deutungsarbeit selber zu leisten und auf diesem Weg »das >Verfahren ' des Nationalsozialismus aufzudecken - ein Verfahren, das den Nazis ermöglichte, ein ganzes Volk hinter sich zu bringen «. ${ }^{107}$ Freilich hätten »die Zeitumstände« diesen »Neuansatz unterdrückt, der sich gerade der Unterdrückung und Folterung des Menschen durch unterdrückende festgefahrene Denkmuster entgegenzustellen hoffte ${ }^{108}$

Die Konkretisierung dieser verschleierten Aufdeckungsarbeit bleibt dann allerdings etwas allgemein, weil die Analogien zwischen der Geschichte der Witwe Bosca und dem Charakter der beteiligten Personen und der Ideologie und Herrschaftspraxis der Nationalsozialisten dann doch gering sind. Und ebenso fehlt eine stichhaltige Begründung dafür, dass Schickeles literarischer »Neuansatz« weder von zeitgenössischen Experten noch von der Literaturwissenschaft der Nachkriegszeit erkannt werden konnte. Doch darf diese Frage hier offenbleiben. Im Hinblick auf die Problemstellung dieser Tagung und dieses Beitrags ist es wichtig, zu sehen, wie sich die Politikfixierung der Jahre um 1933 auf die Rezeption eines an der Oberfläche eher politikfernen Werks auswirkte: Es erschien, kurz gesagt, als belanglos, und dieses Urteil wirkte fort und wurde erst siebzig Jahre nach dem Erscheinen und den ersten negativen Reaktionen wieder in Frage gestellt. Aber selbst daran zeigt sich noch die Politikfixierung: Hätten Schickeles Tagebuchnotizen und seine brieflichen Äußerungen nicht den Anlass zur mühseligen Aufdeckung (sofern es sich nicht um Unterstellungen handelt) der politischen Bezüge und Anspielungen gegeben, wäre Die Witwe Bosca weiterhin unbeachtet geblieben.

Im Übrigen bleibt zu fragen, wie triftig die von Post-Martens vorgeführte Politikaufdeckung oder -unterstellung ist und welche Bedeutung der immense

105 Schickele: Die Witwe Bosca (s. Anm. 99), S. $312 \mathrm{ff}$.

106 Post-Martens: PAN-Logismus (s. Anm. 101), S. 132.

107 Ebd., S. $233 \mathrm{f}$.

108 Ebd., S. 197. 
analytisch-interpretatorische Aufwand im Hinblick auf die Qualität der Witwe Bosca als zeitanalytisches Werk hat. Er offenbart ja auch eine gewaltige Diskrepanz zwischen dem brieflich von Schickele gegenüber dem Grafen Kessler bekundeten analytischen Anspruch und dem erreichten Demonstrationseffekt. Für ein Kunstwerk, das Wirkung sucht, ist das allemal ein Manko. Post-Martens versucht, dieses auszuräumen, indem sie zum einen auf Schickeles Absicht des »hermetischen « ${ }^{109}$ Schreibens verweist (was das Manko aber nicht verringert), zum andern den Roman unter Verweis auf die Theorien von Deleuze, Guattari und anderen als einen ganz neuartigen ausgibt. Dies ist noch weniger überzeugend als die politisch konkretisierende Deutung vieler Einzelmomente, weil alle Arten der textuellen Korrespondenzen, die dann vor Augen geführt werden, weder neu sind noch der neuesten Literaturtheorien bedürfen, um erkannt zu werden. Ließe sich alles, was Post-Martens über die angebliche Neuartigkeit von Der Witwe Bosca sagt, nicht mit ebenso viel oder gar noch mehr Recht über den Zauberberg oder über Berlin Alexanderplatz sagen? So hat man am Ende dieser zweifellos verdienstreichen Arbeit den Eindruck, dass mit Hilfe geeignet scheinender literaturtheoretischer Ansätze versucht wird, ein offenkundiges Manko zu überspielen und Schickeles Roman gemäß dem fortwirkenden Politisierungspostulat als ein politisches Werk zu erweisen und aufzuwerten. Allgemeiner gesagt: Was einer einfachen Hermeneutik, die ihrer Leseerfahrung und ihrer geschulten Verstehens- und Deutungsfähigkeit traut, verborgen zu bleiben scheint, wird mit Hilfe vermeintlich verstehenserweiternder theoretischer Ansätze als eine Bedeutungs- und Qualitätskomponente eines Werks präsentiert, die ohne diesen immensen analytischen Aufwand angeblich nicht wahrnehmbar ist. Vielleicht ist das aber nur eine literaturtheoretisch inspirierte Fiktion und mithin - und schärfer gesagt - eine literaturhistorische Irreführung.

\section{Ideologisches}

Abschließend sei ein Problem angesprochen, das den Umgang mit Literatur aus der Zeit der Weimarer Republik in besonderer Weise betrifft und belastet: die Verwendung des Ideologiebegriffs und die ideologische Differenz von Nationalsozialismus und Kommunismus.

Gesellschaftlich wirksame oder gar dominante Leitvorstellungen wurden in früheren Zeiten und später mit Blick auf frühere Zeiten vorzugsweise als >Ideen`

109 Ebd., S. 10 (mit Verweis auf Schickeles Gebrauch dieses Wortes im oben zitierten Brief an den Grafen Kessler). 
oder >Ideale (in der Aufklärungszeit) oder »Idee des Vaterlandes« (etwa bei Hölderlin). Sie galten in der Regel als ehrenwert und waren Gegenstand der Ideen- oder Geistesgeschichte, die in den 1920er Jahren eine Blütezeit hatte. ${ }^{110}$ Seit Beginn des 19. Jahrhunderts und insbesondere seit Marx und Engels wird hierfür zunehmend auch der Begriff der >Ideologie verwendet, der im Sinne von Karl Mannheims grundlegendem Buch Ideologie und Utopie (1929) zwar als zunächst wertneutrale Bezeichnung für alle (und selbstverständlich standortgebundenen) gesellschaftlichen Vorstellungen von Welt und Leben oder - kurz - >Weltanschauungen gebraucht werden kann, zumeist aber in dem von Marx und Engels inaugurierten Sinn als pejorative Bezeichnung für ein klassengebunden »falsches« oder trügerisches Bewusstsein oder betrügerisches Verschleierungsmanöver verwendet wird. ${ }^{111}$ Die Zeit der Weimarer Republik war nun zutiefst geprägt durch die beispiellos scharfe Konfrontation zweier Gesellschaftskonzepte oder eben Ideologien, des Kommunismus oder Bolschewismus und des Faschismus in Form des Nationalsozialismus, für die Deutschland zum gemeinsamen »Kampfplatz« wurde. ${ }^{112}$ Neben gravierenden Unterschieden in Begründung und Zielsetzung hatten diese Ideologien - wie schon Zeitgenossen, darunter Bertolt Brecht, ${ }^{113}$ bemerkt haben und die Totalitarismusforschung ${ }^{114}$ inzwischen verdeutlicht hat - einige Gemeinsamkeiten, ${ }^{115}$ die auch in literaturgeschichtlicher Hinsicht von Bedeutung sind: Beide versprachen sie, die Welt oder zumindest den ihnen zufallenden Machtbereich auf revolutionäre Weise im Sinne eines ge-

110 Vgl. Klaus Weimar: Geistesgeschichte. In: Klaus Weimar u. a. (Hg.): Reallexikon der deutschen Literaturwissenschaft. Band 1. Berlin, New York 1997, S. 678-681.

111 Vgl. Detlev Schöttker: Ideologie und Ideologiekritik. In: Klaus Weimar u. a. (Hg.): Reallexikon der deutschen Literaturwissenschaft. Band 2. Berlin, New York 2000, S. 118-122.

112 Vgl. dazu Bogdan Musial: Kampfplatz Deutschland: Stalins Kriegspläne gegen den Westen. Berlin 2008. - Die ersten Kapitel des Buches gelten der sowjetischen West- und Deutschlandpolitik vor dem Beginn von Stalins Herrschaft, betreffen also die ganze Zeit der Weimarer Republik. In den Überlegungen der Bolschewisten zur Ausweitung der in Russland begonnenen »Weltrevolution« spielte Deutschland als »Herz Europas« eine »Schlüsselrolle«.

113 Vgl. Brecht: Werke (s. Anm. 11), Band 27: Journale 2. Berlin, Weimar, Frankfurt a.M. 1995, S. 20 (Eintragung vom 27.10.41) und 158 (Eintragung vom 19.7.43).

114 Aus der Fülle der Literatur, die es zu dieser umstrittenen, aber nicht abwegigen Betrachtungsweise gibt, sei auf zwei bilanzierende Titel verwiesen: Eckhard Jesse (Hg.): Totalitarismus im 20. Jahrhundert: eine Bilanz der internationalen Forschung. Baden-Baden 1996; Wolfgang Wippermann: Totalitarismustheorien: die Entwicklung der Diskussion von den Anfängen bis heute. Darmstadt 1997.

115 Vgl. zu diesem vieldiskutierten Thema zuletzt die besonders prägnanten Ausführungen von Kershaw: Höllensturz (s. Anm. 60), S. 367 ff, sowie Gerd Koenen: Utopie der Säuberung: Was war der Kommunismus? Frankfurt am Main, S. 271-300: "Zweierlei Singularität: Nationalsozialismus 
sellschaftlichen Ideals - Herrschaft der Arbeiterklasse beziehungsweise Herrschaft der arischen Rasse - umzubauen. Beide strebten nach einem totalitären Staat und erhoben einen totalen Anspruch auf die Menschen, die dafür einer unablässigen Indoktrination oder Propaganda und Mobilisierung ausgesetzt wurden. Und beide nahmen dafür auf planvolle Weise die Kultur und zumal die Literatur in Dienst. Diese machte sich in dem Maße, in dem sie sich bereitwillig als ancilla ideologiae zur Verfügung stellte oder widerwillig missbrauchen ließ, mitschuldig an den ungeheuren Verbrechen, die im Namen dieser beiden Ideologien begangen wurden, und verfiel noch während der Herrschaft von Bolschewismus und Nationalsozialismus, spätestens aber nach deren Ende der Kritik und Verurteilung. Allerdings gibt es hier eine Differenz, die im Hinblick auf die literaturgeschichtliche Darstellung und Wertung entsprechender Werke von Bedeutung ist und deswegen mit einem kleinen Exkurs bedacht sei:

Während nämlich der rassistisch-partikularistische Nationalsozialismus total diskreditiert ist, findet der Sowjetkommunismus trotz seiner längst bekannten Verbrechen gegen die Menschlichkeit aufgrund seiner universalistischen Gleichheits- und Wohlstandsversprechungen bis heute bei vielen Historikern die Anerkennung eines im Ansatz positiven Unternehmens. ${ }^{116}$ Das spiegelt sich in der literaturgeschichtlichen Reflexion jener Zeit: Während auf den vom Nationalsozialismus kontaminierten Werken und Autoren ein Schatten liegt, der in vielen Fällen einer damnatio memoriae et abolitio nominis gleichkommt, erfreuen sich die literarischen fellow travelers oder »Mitläufer « beziehungsweise »Weggenossen« des Kommunismus, wie Trotzki sie in seinem Traktat Literatur und Revolution schon 1922 nannte, ${ }^{117}$ bleibender literaturgeschichtlicher Aufmerksamkeit und Anerkennung.

Man braucht, um dies zu sehen, nur die Online-Version der Bibliographie der deutschen Sprach- und Literaturwissenschaft zu öffnen und die Namen einiger Autoren aufzurufen, die als »Weggenossen« der einen oder der anderen Ideologie gelten, und die Zahl der bibliographischen Einträge (für Aufsätze,

und Stalinismus im Vergleich«; Frank-Lothar Kroll, Barbara Zehnpfennig (Hg.): Ideologie und Verbrechen: Kommunismus und Nationalsozialismus im Vergleich. München 2014.

116 Das zeigt sich schon bei Thomas Mann, der 1939 in seinem Essay Das Problem der Freiheit den Nationalsozialismus, weil ihm »jede Beziehung [...] zur Menschheitsidee und zur Idee der Vervollkommnung der menschlichen Gesellschaft« fehlte, während dergleichen »bei der proletarischen russischen Revolution « "wenigstens anfänglich« gegeben gewesen sei: Thomas Mann: Essays, Band 5 (s. Anm. 75), S. 69.

117 Vgl. Leo Trotzki: Literatur und Revolution. Aus dem Russischen von Frida Rubiner. Wien 1924, S. 40: »Die literarischen Mitläufer der Revolution « / Leo Trotzki: Literatur und Revolution. Aus dem Russischen von Eugen Schäfer und Hans von Riesen. Essen 1994, S. 67: „Die literarischen Weggenossen der Revolution«. 
monographische Abhandlungen und Editionen) zu vergleichen. Ausgewählt wurden hierfür je drei Autoren aus beiden >Lagern`, die für einen Vergleich in Frage zu kommen scheinen. Einige stichwortartige Hinweise, deren zweckdienliche Plakativität man in Kauf nehmen möge, sollen dies verdeutlichen. Auf die Zitation der zugrundeliegenden biographischen Literatur wird verzichtet. - Die ausgewählten Autoren sind:

Hanns Johst (1890-1978): vielbeachteter expressionistischer und zeitkritischer Dramatiker, Ende der zwanziger Jahre Mitglied des nationalsozialistischen Kampfbundes für Deutsche Kultur, 1932 Mitglied der NSDAP, Verfasser des von Nationalsozialisten bejubelten Dramas Schlageter (1933), nach 1933 hohe literaturpolitische Funktionen und enge Verbindung zum SS-Führer Heinrich Himmler, 1949 zunächst als »Mitläufer«, dann als »Hauptschuldiger« eingestuft.

Johannes R. Becher (1891-1958): expressionistischer Lyriker und Dramatiker, 1919 Mitglied der KPD und Verfasser von kommunistischer Kampf- und Propagandadichtung wie Levisite (1926) und Der große Plan (1931), 1928 Mitbegründer und Leiter des Bundes Proletarisch-Revolutionärer Schriftsteller (BPRS), 1933-45 Exil in Moskau, danach Rückkehr mit der »Gruppe Ulbricht« und hohe kulturpolitische Ämter in der DDR.

Erwin Guido Kolbenheyer (1878-1972): zu Beginn der zwanziger Jahre vielbeachteter Romancier, insbesondere aufgrund der Paracelsus-Trilogie (1917-26), 1926 Mitglied der neu gegründeten nationalen >Dichterakademie` und dort bald Wortführer der >völkischen` Fraktion, karrieresüchtige Annäherung an NS-Funktionäre, nach 1933 mit Ehrungen und Preisen überhäuft, 1948 als »Belasteter«, 1950 als »Mitläufer« eingestuft.

Lion Feuchtwanger (1884-1958), vielgelesener Romancier und Dramatiker aus jüdischer Familie mit »linksbürgerlicher « Einstellung, erfolgreich mit historischen und zeitkritischen Romanen wie Jud Süß (1925) und Erfolg (1930), ab 1933 Exil zunächst in Frankreich, dann in den USA, Anfang Dezember 1936 bis Anfang Februar 1937 Reise in die Sowjetunion mit langem Aufenthalt in Moskau und Gespräch mit Stalin.

Ina Seidel (1885-1979), in den zwanziger und dreißiger Jahren vielgelesene Lyrikerin und Erzählerin bürgerlicher Provenienz und christlicher Einstellung, berühmt durch ihren Roman Das Wunschkind (1931), nach 1933 einige Sympathiebekundungen für Hitler und das >Dritte Reich`, aber auch Distanzsignale.

Anna Seghers (1900-1983), Erzählerin aus einer jüdischen Familie, 1928 Eintritt in die KPD und 1929 in den BPRS, Verfasserin von kommunistischen Revolutionserzählungen wie Aufstand der Fischer von St. Barbara (1928) und Die Gefährten (1932), 1933 Exil zunächst in Frankreich, dann in Mexiko, Weltruhm durch den KZ- und Volksfrontroman Das siebte Kreuz (1942), 1947 Rück- 
kehr nach Berlin (Ost), 1952-78 Präsidentin des DDR-Schriftstellerverbandes und Trägerin hoher Auszeichnungen.

Wenn man nun die Verzeichnisse der Bibliographie der deutschen Sprachund Literaturwissenschaft aufruft, so ergeben sich für den Zeitraum von etwa 1980 bis 2008, der online zugänglich ist, folgende Zahlen: für Hanns Johst 32; für Johannes R. Becher hingegen 232; für Erwin Guido Kolbenheyer 15, für Lion Feuchtwanger 361; für Ina Seidel 23, für Anna Seghers 812. Eine ähnliche Diskrepanz zeigt sich im forschungs- und editionspraktischen Umgang mit solchen Autoren. In einem 2015 publizierten Aufsatz einer verdienten und schätzenswerten Literaturhistorikerin über die Entnazifizierungsakte von Kolbenheyer heißt es einleitend: »Wozu dieses Konvolut nach 65 Jahren noch einmal öffnen? Wer liest heute noch Kolbenheyer (außer den eifrigen Mitgliedern der Kolbenheyer-Gesellschaft e.V.)? « ${ }^{118}$ Kolbenheyers Werk wird - vermutlich ohne Einblicknahme - verworfen, obwohl es literaturgeschichtlich gute Gründe gibt, die Paracelsus-Trilogie, ${ }^{119}$ und nicht nur sie, zur Kenntnis zu nehmen; die Beschäftigung mit Lebensdokumenten geschieht im Rahmen einer Aufarbeitung des Umgangs mit dem Nationalsozialismus nach 1945 und scheint allein dadurch gerechtfertigt zu sein. Anders bei Feuchtwanger: Nicht nur, dass seine Romane in hohen Auflagen verkauft werden, permanent Gegenstand wissenschaftlicher Untersuchungen sind und - zu Recht - mit anerkennenden Wertungen bedacht werden. Es gibt mehrere biographische Darstellungen jüngeren Datums. ${ }^{120}$ Seine blinde Bewunderung für das brutale Sowjetsystem und den Massenmörder Stalin wird als zeitbedingter Irrtum erklärt und tut seiner literaturgeschichtlichen Beachtung und Wertschätzung keinen Abbruch. Die euphemistische Darstellung seiner Reise nach Moskau und seines Gesprächs mit Stalin wurde ediert und nach allen Regeln der Kunst analysiert und erörtert, ${ }^{121}$ ebenso sein

118 Vgl. Hiltrud Häntzschel: „Erspart Kolbenheyer das Schicksal Tassos«: Einblicke in eine Spruchkammerakte. Mit einer Stellungnahme von Erich Kästner. In: Günter Häntzschel, Sven Hanuschek, Ulrike Leuschner (Hg.): Die große Schuld. München 2015, S. 125-147, Zitat S. 125.

119 Vgl. dazu Angelika Straubenmüller: Erwin Guido Kolbenheyers Paracelsus-Trilogie und der »Antimoderne Transfragmentarismus«. Würzburg 2016.

120 Wilhelm von Sternburg: Lion Feuchtwanger: ein deutsches Schriftstellerleben. Berlin 1999 und 2014 (überarbeitete Auflage des Originals von 1983); Andreas Heusler: Lion Feuchtwanger. Münchner - Emigrant - Weltbürger. Salzburg 2014; Andreas Rumler: Exil als geistige Lebensform. Brecht + Feuchtwanger. Ein Arbeitsbündnis. Berlin 2016.

121 Vgl. neben vielen Aufsätzen Karl Kröhnke: Lion Feuchtwanger - Der Ästhet in der Sowjetunion: ein Buch nicht nur für seine Freunde. Stuttgart 1991, sowie Anne Hartmann: »ich kam, ich sah, ich werde schreiben«. Lion Feuchtwanger in Moskau 1937: eine Dokumentation. Göttingen 2017. 
Tagebuch, das neben seiner Blindheit auch seine frivole Rücksichtslosigkeit offenbart. $^{122}$

$\mathrm{Zu}$ erklären ist diese frappierende Disparität durch ein Bündel von unterschiedlichen - nämlich politisch-biographischen, institutionellen und ideellen Umständen, die wiederum knapp benannt seien. Politisch-biographisch: Johst, Kolbenheyer und Seidel sind durch ihre Nähe zum Nationalsozialismus diskreditiert; Kolbenheyer und Seidel gelten als Mitläufer, Johst sogar als Mittäter. Becher, Feuchtwanger und Seghers waren Opfer des von Johst, Kolbenheyer und Seidel unterstützten Terror-Regimes. Die literaturwissenschaftliche Beschäftigung mit diesen ist fast ehrenrührig und bedarf der ausdrücklichen Begründung, während die Beschäftigung mit jenen immer noch mit Rettung und Wiedergutmachung konnotiert ist. Institutionell: Johst, Kolbenheyer und Seidel wurden spätestens in den 1960er Jahren aus dem Register der lesenswerten und behandlungswürdigen Autoren gestrichen, während Becher, Feuchtwanger und Seghers seitens der DDR-Germanistik und dann der aufblühenden Exil-Forschung dauerhafte Beachtung und Wertschätzung fanden. Das zeigt sich auch in der Präsenz auf dem Buchmarkt, die wiederum auf Forschung und Lehre zurückwirkt. Ina Seidels Wunschkind wurde zuletzt 1987 aufgelegt. Wer heute ein Seminar zum Beispiel über Literatur von Frauen in der Weimarer Republik halten will, muss auf die rund 180 Exemplare zurückgreifen, die bei ZVAB angeboten werden, eine Zahl, die für eine große frühere Verbreitung spricht; Anna Seghers' Aufstand ist hingegen im Buchhandel jederzeit als preis-

122 Vgl. Lion Feuchtwanger: Ein möglichst intensives Leben: die Tagebücher. Hg. von Nele Holdack, Marje Schuetze-Coburn und Michaela Ullmann unter Mitarbeit von Anne Hartmann und Klaus-Peter Möller. Mit einem Vorwort von Klaus Modick. Berlin 2018. - Zum Thema Rücksichtslosigkeit: Am 23. und 24. Januar 1937 beobachtete Feuchtwanger den Schauprozess gegen den KP-Funktionär Karl Radek, der während der deutschen Revolution 1918/19 eine gewisse Rolle spielte und in den 1920er Jahren für die Sowjetführung als Deutschlandexperte tätig war. Die Verhängung der Todesstrafe war nicht nur möglich, sondern wahrscheinlich. Am 25. Januar hielt Feuchtwanger im Tagebuch fest: »In der Frühe mit Eva [= Eva Herrmann, eine seiner Geliebten] gevögelt. Nicht zum Prozeß gegangen. Meine Äußerungen zum Prozeß erscheinen groß in der Sowjetpresse. [...]« (ebd., S. 409). Die Vokabeln »gevögelt« und »gehurt« sind wohl die am meisten gebrauchten Verben in diesem Tagebuch; sie tauchen - laut editorischer Notiz - rund 750bzw. 650-mal auf (ebd., S. 638). Nach der Verurteilung und überraschenden Begnadigung Radeks am 29. Januar dann der merkwürdige Eintrag: »Die Begnadigung Radeks macht alles zweifelhaft und zur Farce« (ebd., S. 409). Offensichtlich hätte Radek zum Tode verurteilt und erschossen werden sollen, damit Feuchtwangers öffentliche Affirmation des Prozesses gerechtfertigt worden wäre. Stattdessen wurde er zu zehn Jahren Arbeitslager »begnadigt«, wo er, wie ein kundiger Prozessbeobachter sogleich prophezeite, vermutlich zwei Jahre später umgebracht wurde: vgl. Wladislaw Hedeler: Chronik der Moskauer Schauprozesse 1936, 1937 und 1938: Planung, Inszenierung und Wirkung. Berlin 2003, S. 127 und 650. 
wertes Taschenbuch zu haben. Ideell: Diese Differenz resultiert aber keineswegs nur aus den genannten politisch-biographischen und institutionellen Umständen, sondern auch aus ideellen oder ideologischen (im Mannheim'schen Sinn): Obwohl im Wunschkind das Leben einer hochgradig emanzipierten Frau zur Zeit der französischen Revolution und der deutschen Befreiungskriege geschildert wird, konnte dieser Roman aufgrund des feudalen Milieus, der politischen Implikationen und der antiquiert wirkenden Schreibweise nicht zu einem >Referenzwerk ` der Frauenbewegung und der feministischen Literaturwissenschaft werden. ${ }^{123}$ Ob es bei diesen Disparitäten bleiben muss und ob ihnen literarische oder literaturgeschichtliche Angemessenheit oder Billigkeit zukommt, ist eine Frage, die hier nur gestellt werden kann.

\section{Zusammenfassung}

Um 1910 wurde in verstärktem Maß eine Hinwendung der Literatur zur gesellschaftlichen Wirklichkeit und $\mathrm{zu}$ aktuellen politischen Problemen gefordert; der »Aktivismus« mit seinen programmatischen Artikeln, Zeitschriften und Vereinigungen ist Ausdruck dieses Verlangens. Der Beginn des Ersten Weltkriegs 1914 führte dann, wie am Beispiel von Alfred Döblin und Thomas Mann zu sehen ist, zu einer signifikanten Politisierung des Bewusstseins und des literarischen Schaffens, die, wie am Beispiel Döblins zu erkennen ist, durch die russische Revolution 1917 und erst recht durch die deutsche Revolution 1918/19 erneuert und verschärft wurde. Die sichtbare Einbeziehung sozialer und politischer Umstände wurde zur unabweisbaren Forderung und Aufgabe. Eine Rückkehr in die »machtgeschützte Innerlichkeit (Thomas Mann) der Vorkriegszeit war nicht möglich; Thomas Manns Versuche, sich in die heile Privatwelt von Herr und Hund und Kindchen zu retten, blieb Episode. Am Beispiel von Thomas Manns Zauberberg (1924) und Kurt Tucholskys Schloß Gripsholm (1932) ist zu beobachten, wie aktuelle politische Probleme oder Befindlichkeiten in einen

123 Vgl. dazu Irmgard Hölscher: Geschichtskonstruktion und Weiblichkeitsbilder in Ina Seidels Roman >Das Wunschkind ‘ und Regina Dackweiler: Zur Rezeptionsgeschichte von Ina Seidels `Das Wunschkind ‘, beide in: Barbara Determann, Ulrike Hammer, Doron Kiesel (Hg.): Verdeckte Überlieferungen: Weiblichkeitsbilder zwischen Weimarer Republik, Nationalsozialismus und Fünfziger Jahren. Frankfurt a.M. 1991, S. 41 bzw. 83-104. - Eine Neubewertung zeigt sich bei Nina Nowara-Matusik: "Da die Tränen der Frauen stark genug sein werden ...«: zum Bild der Frau im Erzählwerk Ina Seidels. Katowice 2016, bes. S. 225 ff. 
zunächst politikfernen Vorkriegsroman beziehungsweise in eine im Ansatz unpolitische Urlaubsgeschichte nach dem Muster von Rheinsberg (1912) eindringen. Beide Werke sind Beispiele für Veränderungen in den eingangs genannten Relationen Text / Kontext oder Werk / Gesellschaft und Autonomie / Funktion oder Literaturbezug / Gesellschaftsbezug. In der Relation Text / Kontext ist eine Verdichtung der sozialen und politischen Bezüge $\mathrm{zu}$ beobachten, in der Relation Autonomie / Funktion eine Aufwertung der funktionalen Aspekte. Literatur wurde mehr als je zuvor Spiegel politischer Umstände und Ausdruck politischen Problembewusstseins oder gar Lösungswillens, was sich in prononcierter Form an Hans Grimms deutschem `Schicksalsroman`Volk ohne Raum (1926) zeigt. Sie forderte damit neben oder sogar vor dem ästhetischen das politische Urteil heraus, wobei das ästhetische und das politische Urteil zusammenfallen oder auseinandertreten konnten, und dies - im Fall von Volk ohne Raum - nicht nur zwischen zwei Kritikern prinzipiell gleicher politischer Couleur (Max Herrmann-Neiße und Kurt Tucholsky), sondern auch innerhalb eines einzigen Wertungsprozesses (bei Herrmann-Neiße). Eine literaturgeschichtliche Darstellung muss dem durch eine Wiedergabe der divergierenden Urteile und eine Erörterung der Wertungsproblematik Genüge tun.

Mit der aktualisierenden politischen Aufladung der Werke gerieten diese notwendigerweise in Berührung mit Sachverhalten und Ideologien, also mit Kontexten, deren Beurteilung bis heute umstritten ist und über deren Bedeutung für die literarästhetische Wertung und literaturhistorische Einschätzung eines Werks nicht leicht zu befinden ist. Die Figur des jüdisch-jesuitisch-bolschewistischen Erlösungsfanatikers Leo Naphta in Thomas Manns Zauberberg verliert ihre literarische Unschuld, wenn man sie im Kontext der damals gängigen und von Hitler politisch instrumentalisierten These vom jüdischen Charakter des Bolschewismus sieht. Und sie bleibt nicht nur Exempel einer zeitgenössischen politischen Tendenz, die der Autor nur hätte kritisch darstellen wollen. Vielmehr erscheint Naptha, wenn man Thomas Manns Goethe-Rede von 1932 als weiteren Kontext hinzuzieht, als Repräsentant von politischen Einschätzungen und Konzepten, die dem Verfasser nicht ganz fremd waren und die keineswegs anderen, von Thomas Mann nur kritisch zitierten Zeitgenossen - Ernst Jünger zum Beispiel - zugeschoben werden müssen. Die Einbeziehung von Kontexten lässt ein Werk oder eine seiner Komponenten unter Umständen in einem Licht erscheinen, das einer weniger kontextbezogenen Einschätzung widerspricht. Im Fall des Zauberberg-Romans und speziell der zeitgeschichtlich hochinteressanten Figur des Leo Naphta ist die Kontextualisierung, zu der diese Figur geradezu einlädt und zwingt, nicht weit genug getrieben worden. Das wäre anders, wenn Leo Naphta in einem Roman eines >völkischen` aufgetaucht wäre. 
Damit ist der Umstand berührt, dass es in der Rezeption, Erforschung und Beurteilung der Werke von >linken` und >rechten` Autoren (mit oder ohne Partei-Ausweisen) gravierende Unterschiede gibt. NS-affine Autoren wie Hanns Johst, Erwin Guido Kolbenheyer und Ina Seidel werden ausweislich in der Bibliographie der deutschen Sprach- und Literaturwissenschaft sehr viel weniger behandelt und in der Regel sehr viel kritischer gemustert und beurteilt als kommunistisch eingestellte Autoren wie Johannes R. Becher, Lion Feuchtwanger und Anna Seghers. Den einen werden die Verbrechen der Nationalsozialisten angelastet, den anderen die positiven Ziele des Kommunismus zugutegehalten. Sichtweisen, die sich aus dem unterschiedlichen historisch-politischen Umgang mit dem Nationalsozialismus und dem Kommunismus auch in seiner stalinistischen Form, aus dem Kampf gegen die Totalitarismustheorie und aus der massiven Förderung einer parteilichen Literaturwissenschaft in der DDR ergeben haben, beanspruchen bis heute Geltung und wirken sich auf die Wahrnehmung und Beurteilung vieler Werke der 1920er- und zumal der 1930er-Jahre aus. Das mag seine guten und bis heute vertretbaren Gründe haben und sei hier weder kritisiert noch beklagt, sondern nur als ein forschungs- und wertungsrelevanter Umstand benannt.

\section{Schlussbemerkung}

Der vorliegende Artikel verdankt sich zum einen der Einladung zu der Tagung, die in diesem Band dokumentiert ist, zum anderen der vorausgehenden Erarbeitung einer Geschichte der deutschsprachigen Literatur 1918 bis 1933, die 2017 im Münchener Beck-Verlag als Band X der von Helmut de Boor und Richard Newald begründeten Geschichte der deutschen Literatur von den Anfängen bis zur Gegenwart erschienen ist. Vor dem Hintergrund der Referate und Diskussionen der Tagung möchte ich einige einfache Feststellungen treffen. Für mich war, als ich im Jahr 2004 begann, aufgrund meiner literaturwissenschaftlichen Sozialisation völlig fraglos, dass eine Literaturgeschichte eine gesellschaftsgeschichtliche Fundierung haben müsse, also - von literarischen Werken ausgehend - soziale und politische Prozesse und Diskurse in die Darstellung mit einbeziehen und in Wertungen mit bedenken müsse. Darin sah ich mich durch zahlreiche Äußerungen von Autoren jener Zeit bestätigt, so zum Beispiel durch Thomas Mann, der in seiner Ansprache zur Gründung der »Sektion für Dichtkunst der Preußischen Akademie der Künste« am 26. Oktober 1926 die »Sozialität« seines »Dichter- 
tums « betonte. ${ }^{124}$ Über die Konzeption war ich mir weniger klar, weil das durch de Boor und Newald begründete Muster einer gattungs- und epochenorientierten Literaturgeschichte immer wieder in Frage gestellt worden war. Es gab damals theoretische Konzeptionen von höchster Differenziertheit und Brillanz, ${ }^{125}$ deren praktische Umsetzung über Präliminarien und Fallbeispiele allerdings nie hinauskam. Zudem erschien 2004 Eine Neue Geschichte der deutschen Literatur, die, um dem »Eigensinn der Literatur « und der »Einzigartigkeit « der Werke gerecht zu werden, ${ }^{126}$ die systematische Darstellungsweise preisgab und als Präsentationsform die simpel chronikalische und gänzlich unvermittelte Aneinanderreihung von Titeln und Erörterungen wählte. Das schien eine Alternative zu sein, die sich indessen bei näherem Hinsehen als scheinhaft und defizitär erwies. Scheinhaft ist diese Alternative, weil die Artikel, sobald sie über die bloße Registratur des Titels und die reine Beschreibung (soweit dies überhaupt möglich ist) von Inhalt und Form hinausgehen, zu eben der Integration in Reihen und Zusammenhänge übergehen, die vermieden werden sollte. So stehen die Werke plötzlich wieder im »Schnittpunkt mannigfacher Bezugssysteme«, wie mit Erwin Panofsky in salvierender Absicht gesagt wird, oder zeigen sich »Wechselwirkungen « und »Konfigurationen historischer Tatsachen «, die man dann mit Walter Benjamin in ebenfalls salvierender Absicht "Konstellationen « nennt. ${ }^{127}$ Nichts anderes hat Literaturgeschichtsschreibung, sofern sie nicht ganz einseitig auf einen Aspekt fixiert war, seit eh und je ansichtig zu machen versucht; noch einmal sei auf Uwe Japps profunde Bestimmung von Literaturgeschichte als »Beziehungssinn« (1980) verwiesen. Defizitär ist die chronikalische Alternative zunächst einmal, weil sie die Auswahl nicht explizit begründet. Mit der Frage, warum für das Jahr 1924 Arthur Schnitzlers Novelle Fräulein Else als signifikanter Text gewählt, Thomas Manns Roman Der Zauberberg aber nicht einmal erwähnt wurde, bleibt man als Leser allein und ratlos stehen. Defizitär ist die chronikalische Alternative ferner, weil sie weder thematische Korpora - etwa »Literatur der Arbeitswelt« - bildet, noch entsprechende Beziehungen zwischen den ausgewählten

124 Thomas Mann: Rede zur Gründung der Sektion für Dichtkunst der Preußischen Akademie der Künste. In: Essays, Band 3 (s. Anm. 57), S. 40-44, Zitat S. 42.

125 Statt einzelner Titel nenne ich die zusammenfassende und bereits historisierende Reflexion von Jörg Schönert: Vielerlei Leben der Literaturgeschichte? In: Matthias Buschmeier, Walter Erhart, Kai Kauffmann (Hg.): Literaturgeschichte: Theorien - Modelle - Praktiken. Berlin 2014, S. 31-48, hierzu bes. S. 32-35.

126 Vgl. David E. Wellbery, Judith Ryan, Hans Ulrich Gumbrecht, Anton Kaes, Joseph Leo Koerner, Dorothea E. von Mücke (Hg.): Eine Neue Geschichte der deutschen Literatur. Berlin 2007, S. 15.

127 Vgl. ebd., S. $21 \mathrm{f}$. 
Texten herstellt; die Möglichkeit, sich über einzelne thematische Gebiete oder Textreihen im begründeten und einigermaßen geschlossenen Zusammenhang zu informieren, gibt es nicht. Für die Konzeption meiner Literaturgeschichte 1918-1933 zu spät kam der 2014 publizierte Aufsatzband Literaturgeschichte: Theorien - Modelle - Praktiken, ${ }^{128}$ doch hätte er mich, auch wenn er schon früher erschienen wäre, nicht zu einer grundsätzlichen Änderung meines Konzepts veranlasst; die dort entworfenen Alternativen - »Literaturgeschichte semantischer Einheiten«, »Literaturgeschichte der Intensität - mögen sehr interessant sein, würden aber immer nur zu Literaturgeschichten mit einem sehr beschränkten Fokus oder Erfassungsbereich führen. Wenig hilfreich war der Versuch, Methoden des Dekonstruktivismus und Perspektiven verschiedener turns analytisch und dispositionell zu nutzen; die einen delegitimieren, indem sie die Möglichkeit bündiger Interpretationen verneinen, auch die historiographische Verortung von Texten, die anderen führen zu vereinseitigender Auswahl unter spezifischen Gesichtspunkten. Alles in allem sah und sehe ich $\mathrm{zu}$ einer gesellschaftsgeschichtlich fundierten Literaturgeschichte, $\mathrm{zu}$ welcher geistes- und kulturgeschichtliche Aspekte per se gehören, keine Alternative. ${ }^{129}$ Die Methoden der Auswahl, Darstellung, Kontextualisierung und Verortung der Texte müssen selbstverständlich im Licht der laufenden Hermeneutik-Debatten reflektiert werden. Aber neu zu erfinden sind sie nicht.

128 Vgl. Literaturgeschichte: Theorien - Modelle - Praktiken (s. Anm. 125).

129 Gestützt fühle ich mich darin durch die turn-kritischen Ausführungen von Wolfgang Riedel aus dem Jahr 2004: vgl. Wolfgang Riedel: Literarische Anthropologie: eine Unterscheidung. In: Wolfgang Braungart, Klaus Ridder, Friedmar Apel (Hg.): Wahrnehmen und Handeln: Perspektiven einer Literaturanthropologie. Bielefeld 2004, S. 337-366, bes. S. 346-348. 